\title{
Circulation in the Ona Basin, southern Drake Passage
}

\author{
Nicolas Barré, ${ }^{1}$ Christine Provost, ${ }^{1}$ Nathalie Sennechael, ${ }^{1}$ and Jae Hak Lee ${ }^{2}$ \\ Received 10 September 2007; revised 10 December 2007; accepted 4 February 2008; published 26 April 2008.
}

[1] Five Argo floats trapped in the Ona Basin, in the southern Drake Passage, provided unprecedented information on the water masses and the circulation present in all the seasons from March 2002 to April 2006. Their profiles recorded evidence of deeppenetrating eddies, interleaving of water masses, and branching of the Southern Front of the Antarctic Circumpolar Current as it meets the Shackleton Fracture Zone. Ten-day mean-velocity estimates at the float parking depth $(2000 \mathrm{db})$ often exceeded $15 \mathrm{~cm} \mathrm{~s}^{-1}$, revealing the intensity of the mesoscale field. Satellite data showed that the trapping period of the floats corresponded to the presence of an anticyclonic meander of the polar front over a depression in the topography to the northwest of the Ona Basin. The presence of this meander seems to be linked to low-frequency modes of variability in sea surface height in the Yaghan Basin.

Citation: Barré, N., C. Provost, N. Sennechael, and J. H. Lee (2008), Circulation in the Ona Basin, southern Drake Passage, J. Geophys. Res., 113, C04033, doi:10.1029/2007JC004549.

\section{Introduction}

[2] Drake Passage (DP) is the best documented sector of the Southern Ocean, since it is where the Antarctic Circumpolar Current (ACC), the world's largest current in terms of volume and mass transport, is constricted to its narrowest extent (about $700 \mathrm{~km}$ ) [e.g., Nowlin et al., 1977; Bryden, 1979; Sprintall, 2003]. The ACC is closely associated with three deep-reaching oceanic frontal systems, from north to south: the Subantarctic Front (SAF), the Polar Front (PF), and the Southern ACC Front (SACCF). The Southern Boundary of the ACC (SBdy), farther south, separates ACC water from subpolar water [Nowlin et al., 1977; Orsi et al., 1995]. The mean location of these deep-reaching fronts reflects the bottom topography (Figure 1).

[3] The seafloor at DP is crisscrossed by a number of fracture zones and ridges that delimit small basins often textured with abyssal hills or depressions (Figure 1). The two major features are: (1) the Shackleton Fracture Zone (SFZ), which acts as a barrier to the ACC in the southern half of DP where it rises suddenly from a depth of about $4000 \mathrm{~m}$ to about $1500 \mathrm{~m}$, deflecting the ACC fronts northward; and (2) the West Scotia Ridge (WSR) oriented east-west at middistance between the tip of South America and the Antarctic Peninsula. These ridges delimit the Yaghan Basin to the northeast and the Ona Basin to the southeast (Figure 1).

[4] Since the major ACC fronts cross the Yaghan Basin, the circulation in the Ona Basin has received less attention.

\footnotetext{
${ }^{1}$ LOCEAN, UMR 7159 CNRS/UPMC/MNHN/IRD, Université Pierre et Marie Curie, Paris, France.

${ }^{2}$ KORDI, Seoul, South Korea.

Copyright 2008 by the American Geophysical Union. 0148-0227/08/2007JC004549
}

Sea surface height shows much smaller variability in the Ona Basin than in the Yaghan Basin (Figure 2). Most information about the Ona Basin circulation comes from the WOCE SR1 repeat sections, which were performed either in summer or late spring (Figure 1). These sections always encountered one to three deep eddies in the Ona Basin [Cunningham et al., 2003; Brandon et al., 2004]. Cunningham et al. [2003] found that these eddies have weak vertical velocity shears and large bottom velocities, increasing the recirculation transport to values as large as + or $-25 \mathrm{~Sv}$.

[5] Drake Passage, with its rough topography, appears as a "hot spot" for diapycnal mixing [Naveira Garabato et al., 2004]. These authors suggest that the generation of internal waves as current flows impinge on rough bottom topography is the primary energy source for the enhanced mixing. They found more vertically homogeneous values of diapycnal diffusivity to the east of the SFZ than upstream [Naveira Garabato et al., 2004, Figures 3b and 3c].

[6] The broad-scale global array of temperature-salinity profiling floats, known as Argo, is providing a new space and time sampling of the Southern Ocean. Argo deployments began in 2000, and the first Argo float arrived in Drake Passage in March 2002. Between March 2002 and December 2006, 32 floats have passed through Drake Passage, for a total of 567 profiles (region bounded by $70^{\circ}-48^{\circ} \mathrm{W}$ and $54^{\circ}-64^{\circ} \mathrm{S}$, as in Figure 1). The spatial distribution of Argo float profiles in Drake Passage shows an accumulation of profiles to the southwest, in the Ona Basin (Figure 1). The 232 profiles in the Ona Basin were obtained from only 5 floats launched within one degree of $59^{\circ} 30^{\prime} \mathrm{S}$ and $58^{\circ} \mathrm{W}$; that is, just to the east of the SFZ. The ALACE (autonomous Lagrangian circulation explorer) floats deployed in the 1990s and used in Gille's [2003a, 2003b] Southern Ocean analyses did not sample the Ona Basin. Only the floats launched within the Ona Basin 

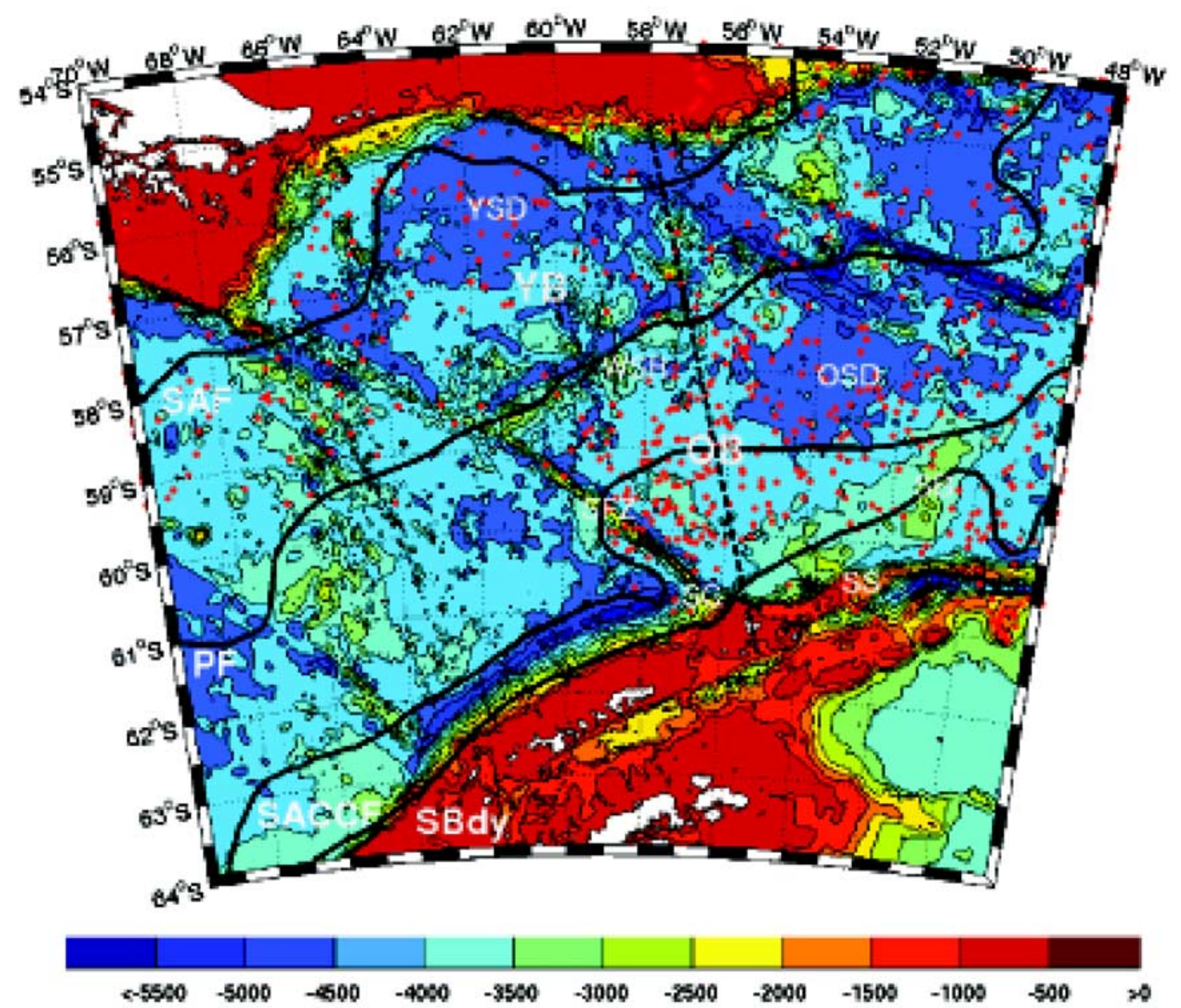

Figure 1. Location of Argo float profiles in the Drake Passage (red dots). Background is the bottom topography: SFZ, Shackleton Fracture Zone; WSR, West Scotia Ridge; SS, Shackleton Shelf; SG, Shackleton Gap; SB, Shackleton Bank; these topographic features delimit the semienclosed Ona Basin (OB). YB denotes Yaghan Basin. Two seafloor depressions (deeper than $5000 \mathrm{~m}$ ) are labeled: OSD, Ona Basin seafloor depression; YSD, Yaghan Basin seafloor depression. The thick black lines indicate the mean location of the major fronts, according to Orsi et al. [1995]; from north to south: SAF, Subantarctic Front; PF, Polar Front; SACCF, South ACC front; SBdy, southern boundary of the ACC. The black star at $60^{\circ} 37^{\prime} \mathrm{S}$ and $53^{\circ} 50.5^{\prime} \mathrm{W}$ indicates the location of a current meter mooring and the thin dotted line indicates the location of the WOCE SR1 repeated hydrographic section.

sampled it and remained trapped there for some time. These floats provided unprecedented all-season information on the water masses and circulation in the Ona Basin during the period March 2002 to May 2006.

[7] The objective of the present work was to examine the Ona Basin hydrography and circulation during the float period, and to investigate why the floats got trapped in the Ona Basin. For this latter purpose we used satellite observations to place the float period in the context of the longer satellite record. The paper is organized as follows. After a presentation of the data used (section 2), the temperature and salinity data from the floats set up the general hydrographic conditions (section 3). Then we examine the circulation, eddy field and mixing in the Ona Basin during the float period (section 4). Possible mechanisms for trapping the floats in the Ona Basin are suggested in section 5, using satellite altimetric data as a framework to put the float period into perspective.

\section{Data and Methods}

\subsection{Argo Floats}

[8] The Argo float program has seeded the world's ocean with about 3000 drifting profiling floats. They drift freely during $10 \mathrm{~d}$ at their parking depth $(2000 \mathrm{db})$ before profiling up to the surface and transmitting the information they have recorded. The data comprise position and date, and temperature and salinity profiles. They are collected and made freely available by the International Argo Project and the national programs that contribute to it. The five Argo floats documenting the Ona Basin were deployed by the British Oceanographic Data Centre at the Proudman Oceanographic Laboratory, Bidston, UK (float 3900069), and by the 


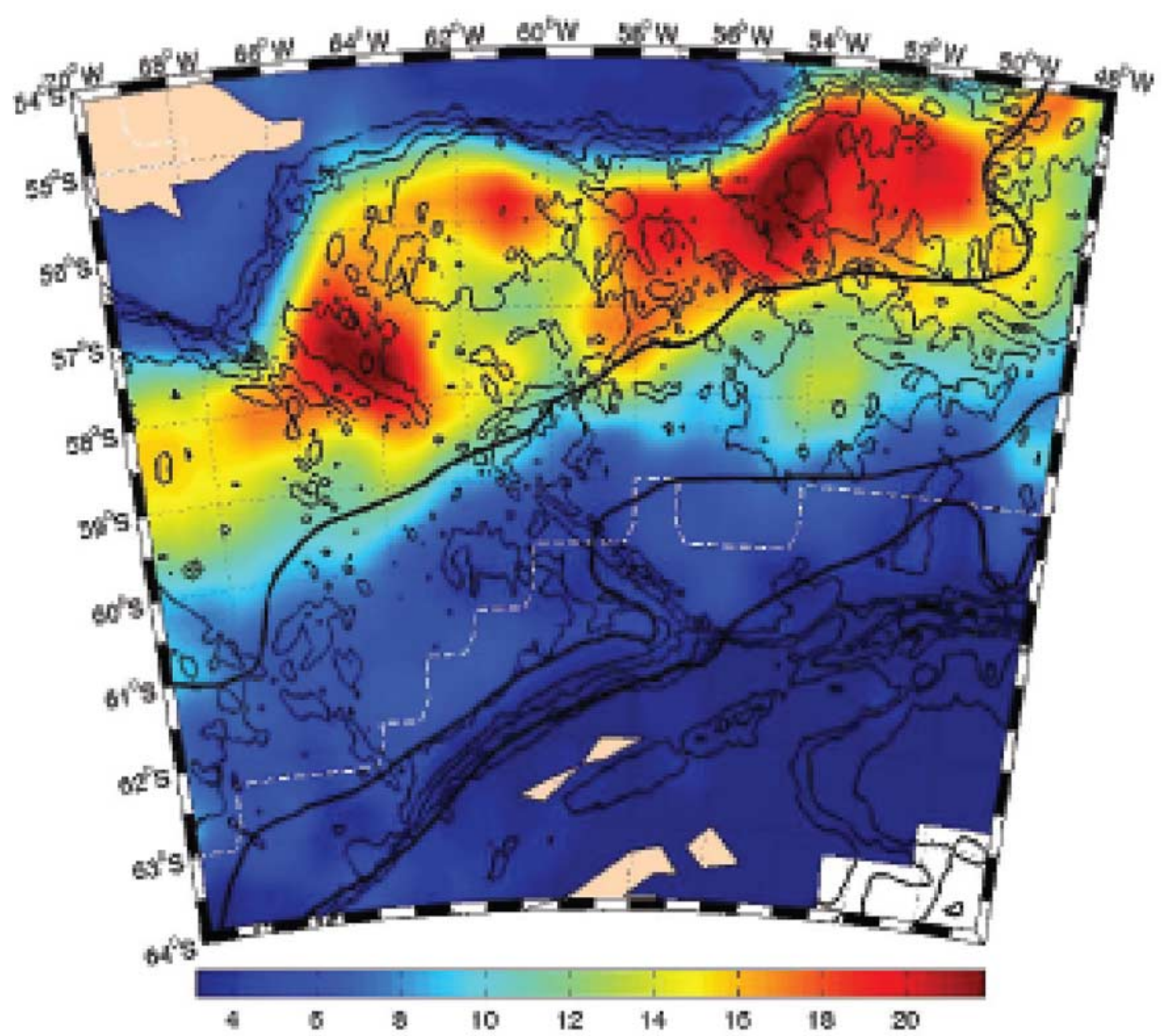

Figure 2. Standard deviation of the sea surface height from October 1992 to December 2006, in centimeters. Mean fronts are located as in Figure 1. The variability is much smaller in the Ona Basin than in the Yaghan Basin. SSH time series are incomplete south of the dotted white line.

Korean Ocean Research and Development Institute (floats 3900195, 3900196, 3900197, and 5900476) within one degree of $59.5^{\circ} \mathrm{S}$ and $58^{\circ} \mathrm{W}$, just east of the Shackleton Fracture Zone (Table 1a and Figure 1). Profiler 3900069 was deployed in March 2002, whereas profilers 3900195,
3900196, 3900197 and 5900476 were launched later, in December 2003. The last float to exit the Ona Basin, float 3900195 , did so around mid-April 2006. Three floats (3900196, 3900197 and 5900476) remained in the Ona Basin for 6 to 10 months; float 3900069 sampled the Ona

Table 1a. Characteristics of the Five Argo Floats Trapped in the Ona Basin

\begin{tabular}{|c|c|c|c|c|c|c|c|c|}
\hline \multirow{2}{*}{$\begin{array}{l}\text { Profiler } \\
\text { Number }\end{array}$} & \multirow[b]{2}{*}{ Type } & \multirow[b]{2}{*}{ Source } & \multicolumn{2}{|c|}{ Deployment } & \multicolumn{2}{|c|}{ Exiting OB } & \multicolumn{2}{|c|}{$\begin{array}{l}\text { Time at the } \\
\text { Surface } \\
\text { (hours) }\end{array}$} \\
\hline & & & Date & Location & Date & Location & Mean & Max \\
\hline 3900069 & APEX & Argo UK & 22 March 2002 & $\begin{array}{c}56.824^{\circ} \mathrm{W} \\
60.169^{\circ} \mathrm{S}\end{array}$ & 12 December 2003 & $\begin{array}{c}48.148^{\circ} \mathrm{W} \\
57.835^{\circ} \mathrm{S}\end{array}$ & 4.2 & 5 \\
\hline 3900195 & APEX & Argo KORDI & 15 December 2003 & $\begin{array}{c}57.133^{\circ} \mathrm{W} \\
59.141^{\circ} \mathrm{S}\end{array}$ & 23 May 2006 & $\begin{array}{c}48.02^{\circ} \mathrm{W} \\
56.85^{\circ} \mathrm{S}\end{array}$ & 4 & 8 \\
\hline 3900196 & APEX & Argo KORDI & 15 December 2003 & $\begin{array}{c}56.389^{\circ} \mathrm{W} \\
59.821^{\circ} \mathrm{S}\end{array}$ & 19 December 2004 & $\begin{array}{l}53.99^{\circ} \mathrm{W} \\
56.336^{\circ} \mathrm{S}\end{array}$ & 3.5 & 5 \\
\hline 3900197 & APEX & Argo KORDI & 14 December 2003 & $\begin{array}{c}58.472^{\circ} \mathrm{W} \\
59.283^{\circ} \mathrm{S}\end{array}$ & 1 July 2004 & $\begin{array}{c}48.433^{\circ} \mathrm{W} \\
56.516^{\circ} \mathrm{S}\end{array}$ & 5 & 10.3 \\
\hline 5900476 & MARVOR & Argo KORDI & 16 December 2003 & $\begin{array}{c}56.824^{\circ} \mathrm{W} \\
60.169^{\circ} \mathrm{S}\end{array}$ & 2 August 2004 & $\begin{array}{c}48.187^{\circ} \mathrm{W} \\
56.875^{\circ} \mathrm{S}\end{array}$ & 11 & 12.3 \\
\hline
\end{tabular}


Table 1b. Vertical Sampling Characteristics

\begin{tabular}{lccc}
\hline & \multicolumn{3}{c}{ Sampling Interval for the Floats, db } \\
\cline { 2 - 4 } & \multicolumn{3}{c}{3900195,} \\
Pressure & 3900069 & 3900196, & 5900476 \\
Interval, db & 10 & 10 & 10 \\
$0-100$ & 10 & 20 & 10 \\
$100-200$ & 20 & 20 & 20 \\
$200-300$ & 30 & 20 & 20 \\
$300-400$ & 50 & 20 & 20 \\
$400-500$ & 50 & 60 & 20 \\
$500-800$ & 50 & 60 & 25 \\
$800-900$ & 50 & 100 & 25 \\
$900-1000$ & 50 & 100 & 50 \\
$1000-1300$ & 50 & 100 & 100 \\
$1300-1400$ & 100 & 100 & 100 \\
$1400-2000$ & &
\end{tabular}

Basin for 20 months and float 3900195, for two and a half years (Table 1a). All these floats had a 2000-db parking depth. At each cycle the time spent at the surface depends on the amount of data to be transmitted and the satellite availability within the transmission time range. It varied between 3.5 and $11 \mathrm{~h}$ on average and never exceeded $12.3 \mathrm{~h}$ (Table 1a). Float 5900476, which had a higher vertical resolution (Table $1 \mathrm{~b}$ ) and thus gathered more data, spent more time at the surface than the other floats.

[9] We used the 232 profiles that passed the Argo realtime quality control; less than $7 \%$ of the profiles were incomplete or missing. Accuracy of salinity observations was checked by comparing the observed values at the float deepest level $(2000 \mathrm{db})$ and CTD observations from the WOCE SR1 repeated sections (Figure 1). This cannot be a precise calibration, as measurements are years apart, and eddy activity is intense. We estimated that the uncertainty in salinity measurements was less than 0.02 . As measurements cover five years of data, we also compared the temperature and salinity data of the floats at their parking depth over those five years and could not detect any trend that would increase the uncertainty. Each profile is made up of about 50 data points, with a vertical resolution varying between $10 \mathrm{db}$ in the surface layer and $100 \mathrm{db}$ below $1400 \mathrm{db}$ (Table 1b). Although these resolutions allow adequate description of water masses and thick thermohaline intrusions, they do not allow computation of values of diapycnal diffusivity as described by Thompson et al. [2007].

[10] The data from float 3900195, which remained in the Ona Basin for two and a half years, and from float 3900196, which crossed the SFZ from east to west, are displayed in Figures $3 \mathrm{a}$ and $3 \mathrm{~b}$, respectively, which include profile location with a "pseudo-trajectory" (linear interpolation between two successive surface positions), and potential temperature and salinity profiles as a function of time. The upper $500 \mathrm{db}$ are enlarged to allow an easier examination of the evolution of the upper layer, in particular its seasonal variations. Profiles of potential-density anomalies help to better distinguish water masses (bottom plots on Figures 3a and $3 \mathrm{~b}$ ). Temperature and salinity profiles were also plotted as a function of potential density to document further the ventilation in winter (see section 3.4).

[11] Float temperature and salinity profiles document water masses at all seasons in a rather homogeneous way (Figure 4). Kriging (Y. Gratton and C. Lafleur, The Matlab Kriging Toolbox, version 4.0, available at http://www.ete. inrs.ca/profs $/ \mathrm{yg} / \mathrm{krig}$.htm) was used to produce twodimensional maps of properties at different pressure and potential density levels. The temperature-salinity distributions were considered isotropic and a search radius of $25 \mathrm{~km}$ was used. We have to keep in mind that these "maps" are not synoptic.

[12] Since the floats drifted freely for $10 \mathrm{~d}$ before profiling up to the surface, a rough estimate of the mean velocity during the subsurface drift can be derived from the distance between two surface positions and the time spent under water between the two successive surfacings. Ichikawa et al. [2002] showed that the mean drift velocity at parking depth may be overestimated by between 10 and 25 percent and that the error due to the vertical current shear has the same order as the error due to surface drift. Such estimates of 10-d mean velocities at the parking depth were computed to document the intensity of the circulation at $2000 \mathrm{db}$ (section 4).

\subsection{Satellite Data}

[13] We used ocean color, sea surface temperature (SST) and sea level anomaly (SLA) data for our spatial and temporal coverage. SST data came from two independent sensors carried on board the Aqua satellite, launched in May 2002: the moderate-resolution imaging spectroradiometer (MODIS) and the advanced microwave scanning radiometer for EOS (AMSR-E). AMSR-E data, with a rather low spatial resolution of a quarter of a degree $(\sim 25 \mathrm{~km})$ and global through-cloud SSTs, are provided by Remote Sensing System (RSS) (www.ssmi.com).

[14] Aqua/MODIS provides an unprecedented ability to measure ocean surface color simultaneously with SST. However, cloud cover is omnipresent in the high latitudes of the study area. We went through the Level-3 data (8-d composites and 4-km-resolution standard mapped image (SMI) data products available through OceanColor FTP $\mathrm{ftp} / / /$ oceans.gsfc.nasa.gov), to select the few clear images available. These high-resolution images reveal a wealth of structures with narrow fronts, eddies, vortices and filaments. An example is shown in Figure 5a.

[15] We used daily and 3-d composite AMSR-E SST products from RSS. These cloud-free data provided a

Figure 3a. Float 3900195 which was trapped for two and a half years in the Ona Basin; (first plot) trajectory is plotted with different colors: blue from cycle 2 to 23 , green from cycle 23 to 48 , pink from cycle 48 to 72 , yellow from cycle 72 to 84 , and red from 84 to 92 ; profiles of (second plot) potential temperature $\left({ }^{\circ} \mathrm{C}\right)$, (third plot) salinity, and (fourth plot) density anomaly, all as a function of time. Density anomaly was computed as: a $\sigma_{\theta}(\mathrm{z}, \mathrm{t})=\sigma_{\theta}(\mathrm{z}, \mathrm{t})-\left\langle\sigma_{\theta}(\mathrm{z})\right\rangle$ where $\left\langle\sigma_{\theta}(\mathrm{z})\right\rangle$, the time-averaged profile of potential density, is plotted to the right of the time plot. Vertical axis is pressure (in db) and is enlarged between 0 and $500 \mathrm{db}$ (by a factor of 2). 

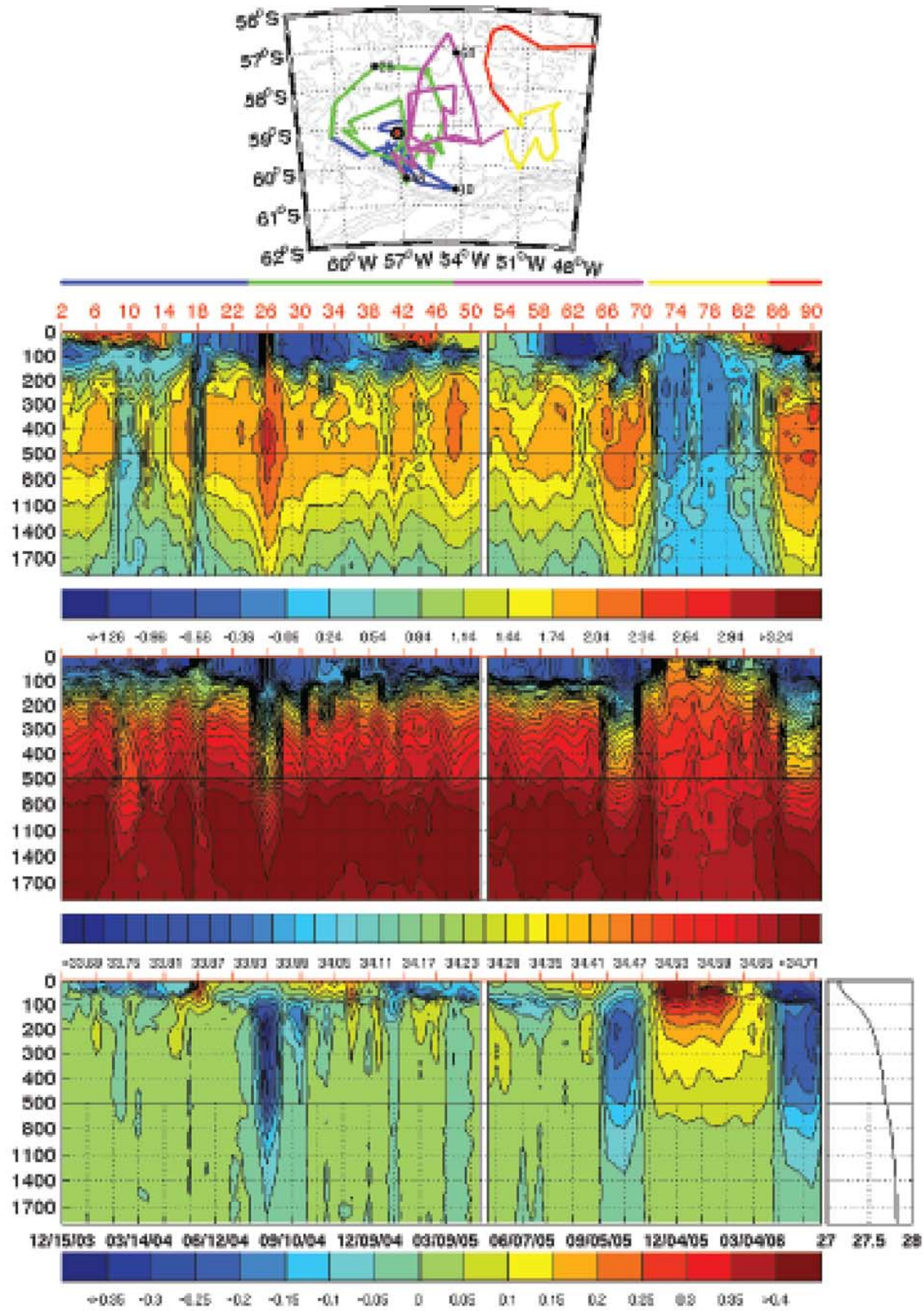

Figure 3a 


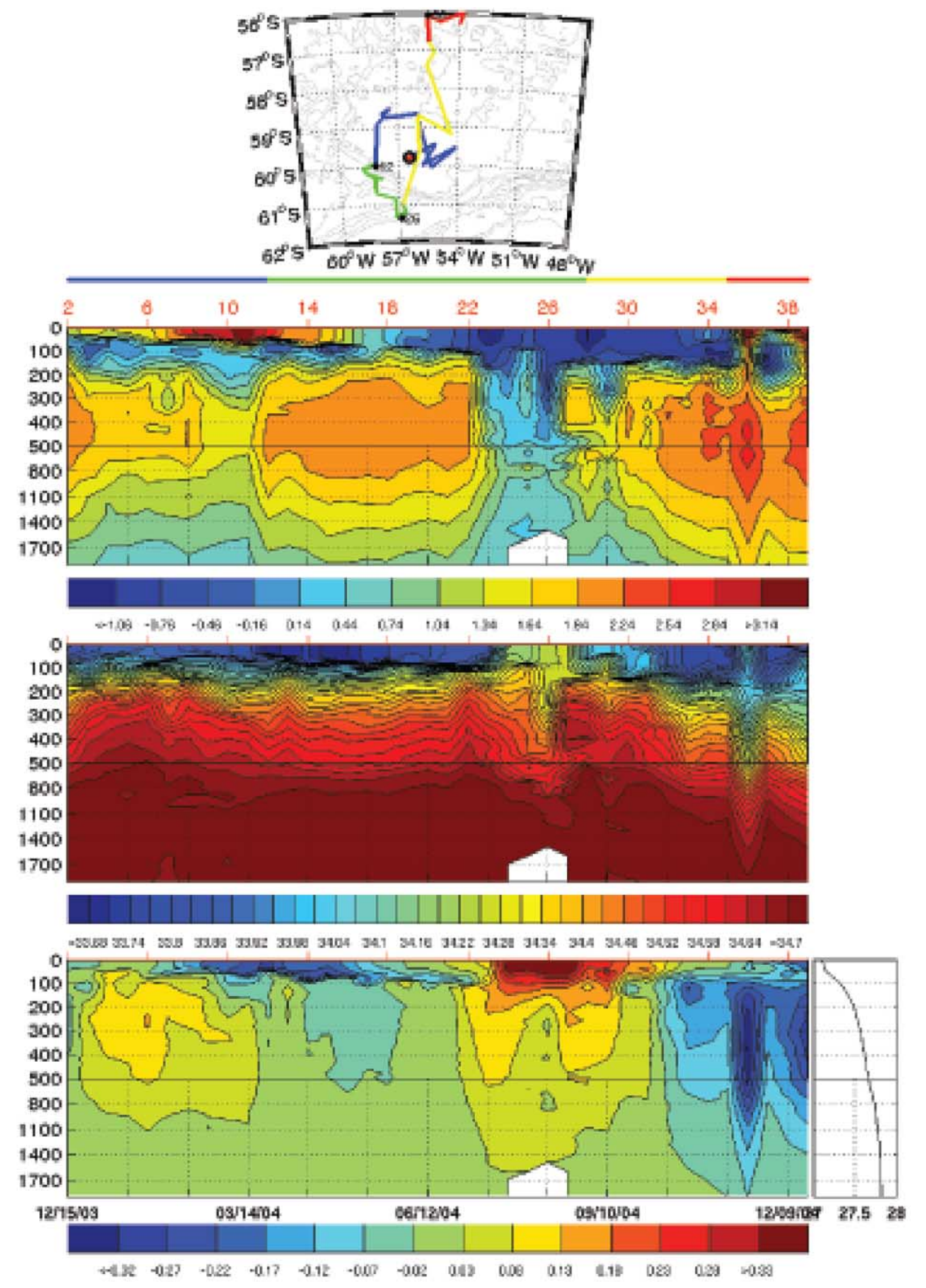

Figure 3b 


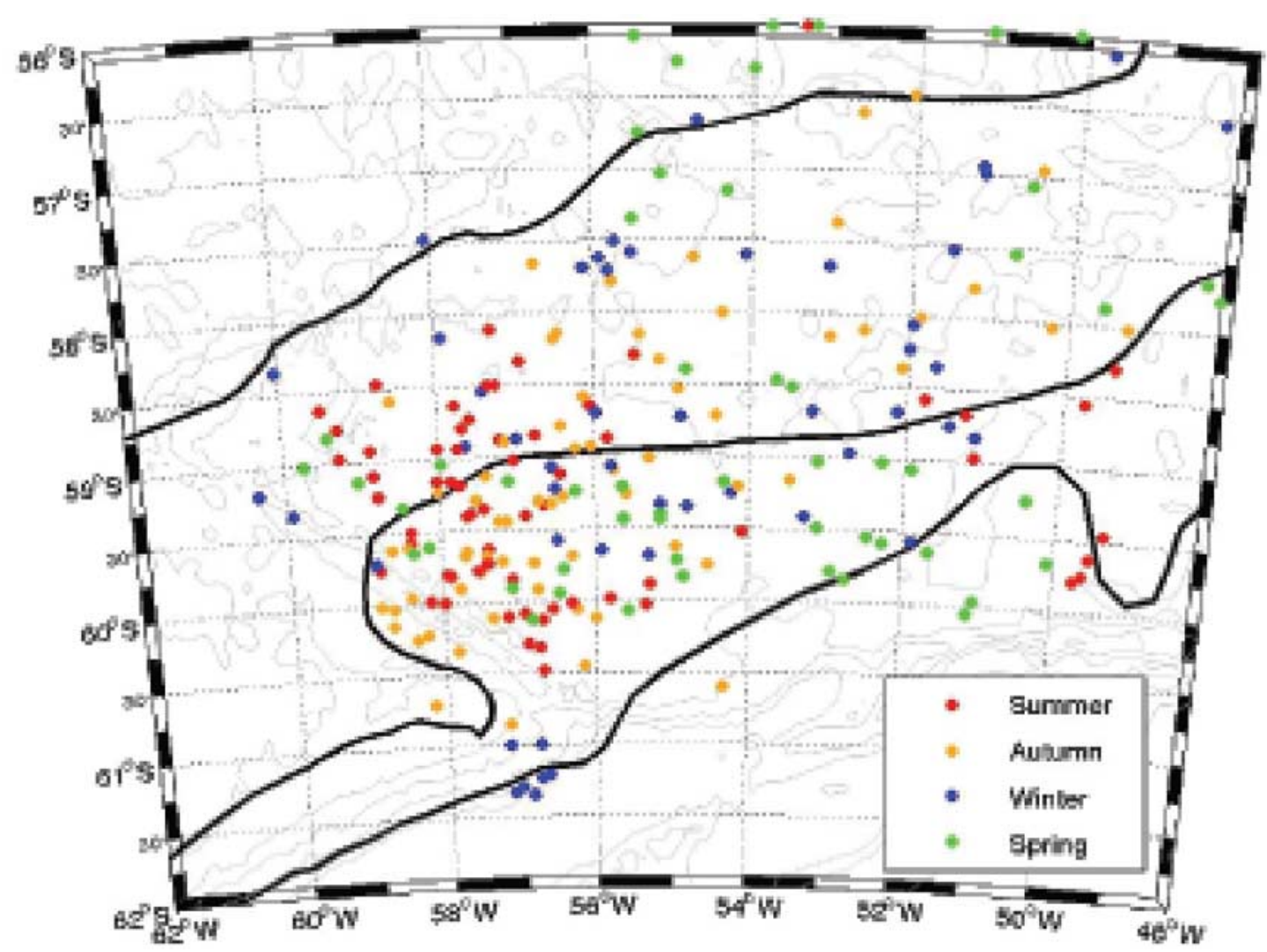

Figure 4. Location of the Ona Basin Argo float profiles as a function of season. Spring (green dots): October, November, and December; summer (red dots): January, February, and March; autumn (blue dots): April, May and June; and winter (orange dots): July, August, and September. Five years are covered, from 2002 to 2006. The thick black lines are as in Figure 1. In gray, isobaths are 0, 1000, 2000, 3000 , and $4000 \mathrm{~m}$.

complete time series of SST over four and a half years with a time resolution particularly useful for detecting the Polar Front location. The Polar Front has a remarkable SST signature [Moore et al., 1999; Dong et al., 2006]. South of $59^{\circ} \mathrm{S}$, there are gaps in the SST retrievals because of areas affected by sun glint, sea ice, rain and/or high wind speed $\left(>20 \mathrm{~m} . \mathrm{s}^{-1}\right.$ ) (www.remss.com). Thus the SST information from AMSR-E south of $59^{\circ} \mathrm{S}$ is rather limited (Figure $5 \mathrm{~b}$ ).

[16] Satellite altimetry provides continuous data since October 1992. We used the merged data set produced by CLS Argos (ftp://ftp.cls.fr/pub/oceano/AVISO/SSH/duacs/ global $/ \mathrm{dt} / \mathrm{upd} / \mathrm{msla} / \mathrm{merged} / \mathrm{h} /)$; that is, gridded maps of sea level anomaly $\left(1 / 4^{\circ} \times 1 / 4^{\circ}\right.$ spatial resolution and a 7 -d time resolution). As indicated by the dashed line on Figure 2, there is a limit to the spatial coverage of altimetry in winter. The processing of along-track data from the altimetric missions TOPEX/Poseidon, Jason-1, ERS-1, ERS-2 and Envisat into weekly fields of SLA is described by Le Traon et al. [2003] We produced maps of absolute dynamic topography (MADT) by adding the SLA fields to the mean dynamic topography (MDT) field of Rio et al. [2005]. The MDT is a combined product based on the GRACE (Gravity Recovery And Climate Experiment) mission, altimetry and in situ data (hydrographic and drifter data). Finally, the geostrophic relationship was used to produce weekly absolute surface-velocity fields for each MADT, with a $1 / 4^{\circ}$ spatial resolution (Figure 5b, top). The similar ocean structures, in terms of meanders and eddies, in the MADT and SST give some credit to the MDT in this region, although surface geostrophic velocity will be used with much caution.

\subsection{Current Meter}

[17] Current meter data from the continental slope at $60^{\circ} 37^{\prime} \mathrm{S}$ and $53^{\circ} 50^{\prime} \mathrm{W}$ document the velocities in the south of the Ona Basin (Figure 1) from 26 November 2003 to 23 December 2004. The data were gathered within the Korean Antarctic Research Program [Lee, 2006; Lee et al., 2007]. Deployment and recovery were both performed from the Russian Research Vessel Yuzmhorgeologia. The mooring

Figure 3b. Trajectory, potential temperature, salinity, and density anomaly (as in Figure 3a) as a function of time for float 3900196, which crossed the SFZ toward the west. The trajectory is plotted with different colors: blue from cycle 2 to 12 , green from cycle 13 to 26 , yellow from cycle 27 to 35 , and red from 35 to 39 . The green part of the trajectory is located on the western side of the SFZ. 

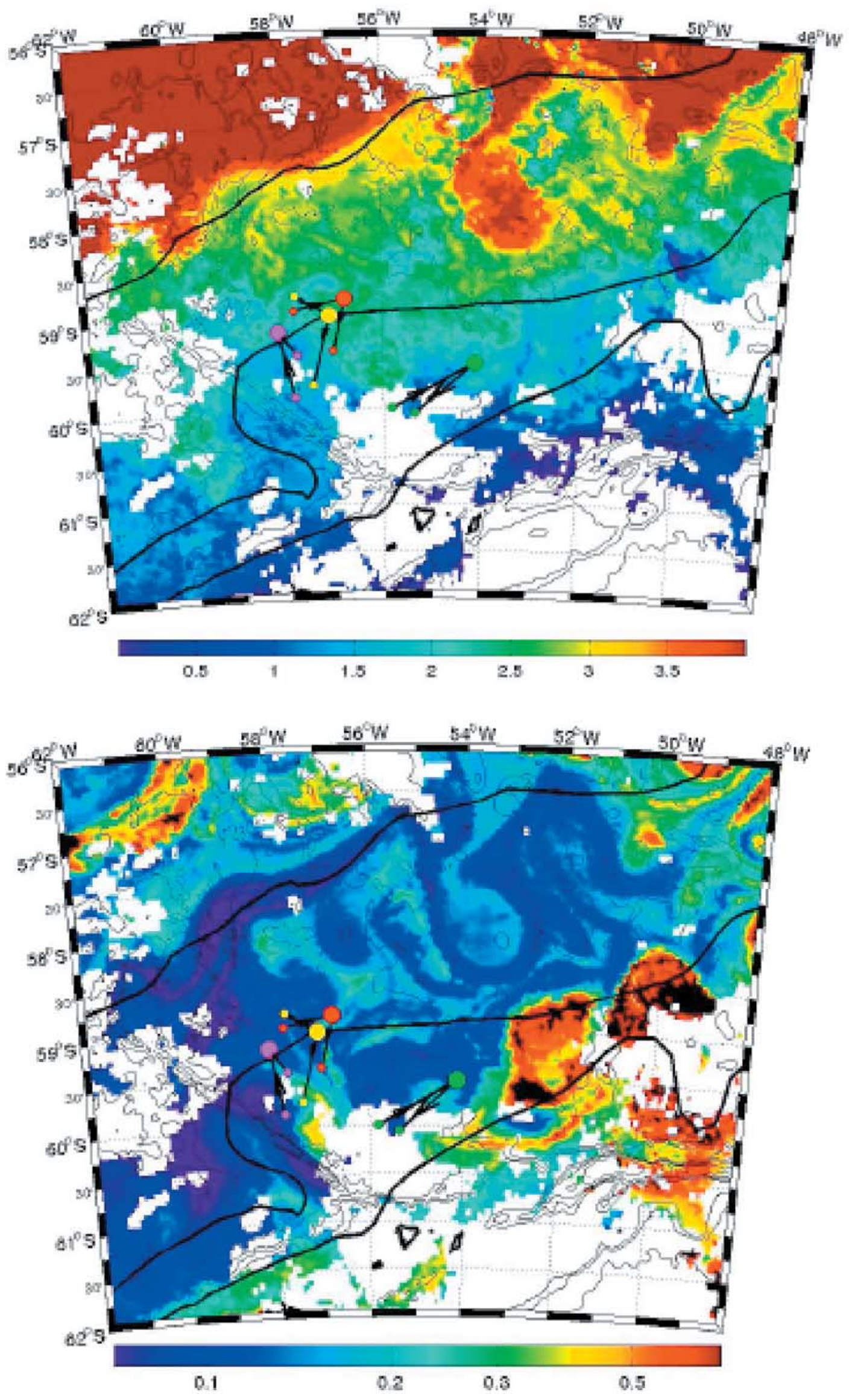

Figure 5a 
comprised 3 Aanderaa vector averaging current meters one RCM 8 at $630 \mathrm{~m}$, one RCM11 at $1100 \mathrm{~m}$ and once RCM11 at $2626 \mathrm{~m}$. The sampling interval was $20 \mathrm{~min}$. The data was then low-passed with a 3-d cutoff and resampled every 12 h (Figure 6). Table 2 summarizes the basic statistics of the velocity measurements. The mooring is severely pulled up and down during strong current pulses over periods of several days (motions caused by tides are negligible). The vertical displacement is of 60 dbar root-mean square for the upper instrument and diminishes with depth (Table 2). Largest displacements exceeded $60 \mathrm{db}$ (reaching up 450 $\mathrm{db}$ at one time) during six events with velocities in excess of $20 \mathrm{~cm} \mathrm{~s}^{-1}$ at the deeper level. Errors were estimated as by Vivier and Provost [1999]: the estimated bias is small (1$2 \%$ ) and the estimated error in the variance reaches values of $15 \%$. Several schemes based on interpolation extrapolation between successive instruments have been proposed to compensate for such errors. However, as instruments are not sufficiently densely sampled to permit an accurate correction, no corrections have been applied to the velocity data. The statistics are attributed to the mean depth of the instruments.

\section{Hydrography}

\subsection{Main Water Masses}

[18] Argo floats provided 232 temperature-salinity profiles in the Ona Basin from March 2002 to April 2006 (Table 1). Two temperature-salinity $(\theta-\mathrm{S})$ diagrams are plotted: one from the winter profiles (Figure 7a) and one from those for the rest of the year (Figure 7b). They permitted identification of the main water masses in the upper $2000 \mathrm{~m}$ (Figure 7).

[19] The coldest water is the Winter Water (WW), the properties of which are set during the austral winter when strong winds mix the surface water and create a thick mixed layer with low temperatures and increased salinity. WW is found between the Polar Front and the SBdy on $\sigma_{\theta}$ surfaces between 27.10 and 27.50, roughly between the surface and $200 \mathrm{~m}$ depth in winter. Indeed, during spring and summer, Antarctic Surface Water (ASW) is formed as the surface waters heat up and cap the WW. The coldest WW, with a temperature of $-1.6^{\circ} \mathrm{C}$, was found around $57.7^{\circ} \mathrm{S}$ and $56^{\circ} \mathrm{W}$ at the end of July 2002. WW salinities spanned a large range of values, from 33.7 to 34.1. ASW thickness never exceeded $70 \mathrm{~m}$, as observed, for example, on the temperature-time plot of the two and a half years of profiles from float 3900195 (Figure 3a). ASW salinity was slightly lower than that of WW. ASW is only found between the Polar Front and the SBdy. Water with surface salinities greater than 34.1 is not ASW, but rather surface water from the Weddell-Scotia Confluence (WSC) south of the SBdy. Its temperature is colder $\left(<1.5^{\circ} \mathrm{C}\right)$ than that of ASW. The mixing of three water types: Weddell Seawater, Scotia Seawater and Antarctic Peninsula shelf water in the WSC leads to a higher salinity and lower temperature found in
ASW [Whitworth et al., 1994]. Circumpolar Deep Water (CDW), with higher $\theta$ and $\mathrm{S}$ values than those of $\mathrm{WW}$, lies below the WW and can be divided into Upper Circumpolar Deep Water (UCDW) and Lower Circumpolar Deep Water (LCDW) (Figure 7). The UCDW corresponds to a subsurface maximum of potential temperature in the range $1.5^{\circ}$ $2.5^{\circ} \mathrm{C}$ and the LCDW, to a local salinity maximum (S around 34.7) and potential temperature between 1.2 and $1.6^{\circ} \mathrm{C}$. Beneath the CDW, $\theta$ and $\mathrm{S}$ both decrease, indicating the presence of Warm Deep Water (WDW), a modified form of LCDW cooler and fresher that has circulated around the Weddell gyre. As the floats do not profile below a depth of $2000 \mathrm{db}$, Weddell Sea Deep Water (WSDW) was only observed to the south of Shackleton Bank (float 3900195, from 24 November 2005 to 12 February 2006, cycles 72 to 84) (Figure 3a). Thus WSDW was only observed to the south in the Weddell-Scotia Confluence where it is found around a $\sigma_{\theta}$ surface of 27.84 at a pressure greater than $1500 \mathrm{db}$. The coldest WSDW encountered had a potential temperature just below $0^{\circ} \mathrm{C}$ and a salinity less than 34.65 .

\subsection{Main Fronts and Intrusions}

[20] Strong gradients in $\theta$-S characteristics provide information on the location of the fronts [Orsi et al., 1995].

[21] The SBdy is defined as the location of the southern boundary of the UCDW. Thus profiles south of the SBdy do not present any UCDW since their potential density, $\sigma_{\theta}$, is greater than 27.75 at $500 \mathrm{db}$. Most of the profiles south of the SBdy (blue dots in Figure 8a) were found to the southeast of the Ona Basin near the Shackleton Bank. A few were also found along the continental slope and shelf to the south and southwest of the Ona Basin. The few blue dots in Figure $8 \mathrm{a}$ west of $56^{\circ} \mathrm{W}$ and north of $60^{\circ} \mathrm{S}$ corresponded to patches of dense water from the south that managed to penetrate quite far north into the Ona Basin, either in the form of cold eddies or of intrusions. These profiles south of the SBdy can be further separated into two groups with very different salinities: the saltier ones, with a salinity greater than 34.68, are typical of LCDW, whereas the fresher ones, with a salinity less than 34.60 , were either located to the southwest and belong to the Weddell-Scotia Confluence, or on the continental slope and corresponding to shelf waters (Figure 9, second row).

[22] The PF has a strong surface-temperature signature [Moore et al., 1999; Dong et al., 2006]. At $500 \mathrm{db}$, it corresponds to the southern limit of warm $\left(>2^{\circ} \mathrm{C}\right)$ and fresh $(<34.5)$ waters and is roughly equivalent to the potential density 27.6. Thus the profiles with a potential density below 27.6 at $500 \mathrm{db}$ (orange dots in Figure 8a) were obtained to the north of the PF. They were located to the north of the Ona Basin, except for one profile near $59^{\circ} 30^{\prime} \mathrm{S}$ and $53^{\circ} 30^{\prime} \mathrm{W}$ corresponding to profile 69 of float 3900195 (Figure 3a).

[23] The SACCF is the only ACC front that does not separate distinct surface water masses: the near-surface water between the PF and SBdy consists of ASW overlying

Figure 5a. Composite satellite images from 9 to 16 January 2004. The float locations during that week, $10 \mathrm{~d}$ before that week, and $10 \mathrm{~d}$ after are: green dots float 3900196, yellow dots float 3900197, red dots float 3900195, and pink dots float 5900476. Float 390069 has already left the Ona Basin. The three floats underwent a cyclonic motion during that period. (top) MODIS 4-km resolution SST (in ${ }^{\circ} \mathrm{C}$ ). (bottom) MODIS 4-km resolution color-derived chlorophyll $a$ concentration (in $\left.\mathrm{mg} / \mathrm{m}^{3}\right)$; note the PF meandering and the chlorophyll $a$ enrichment to the east of the SFZ. 

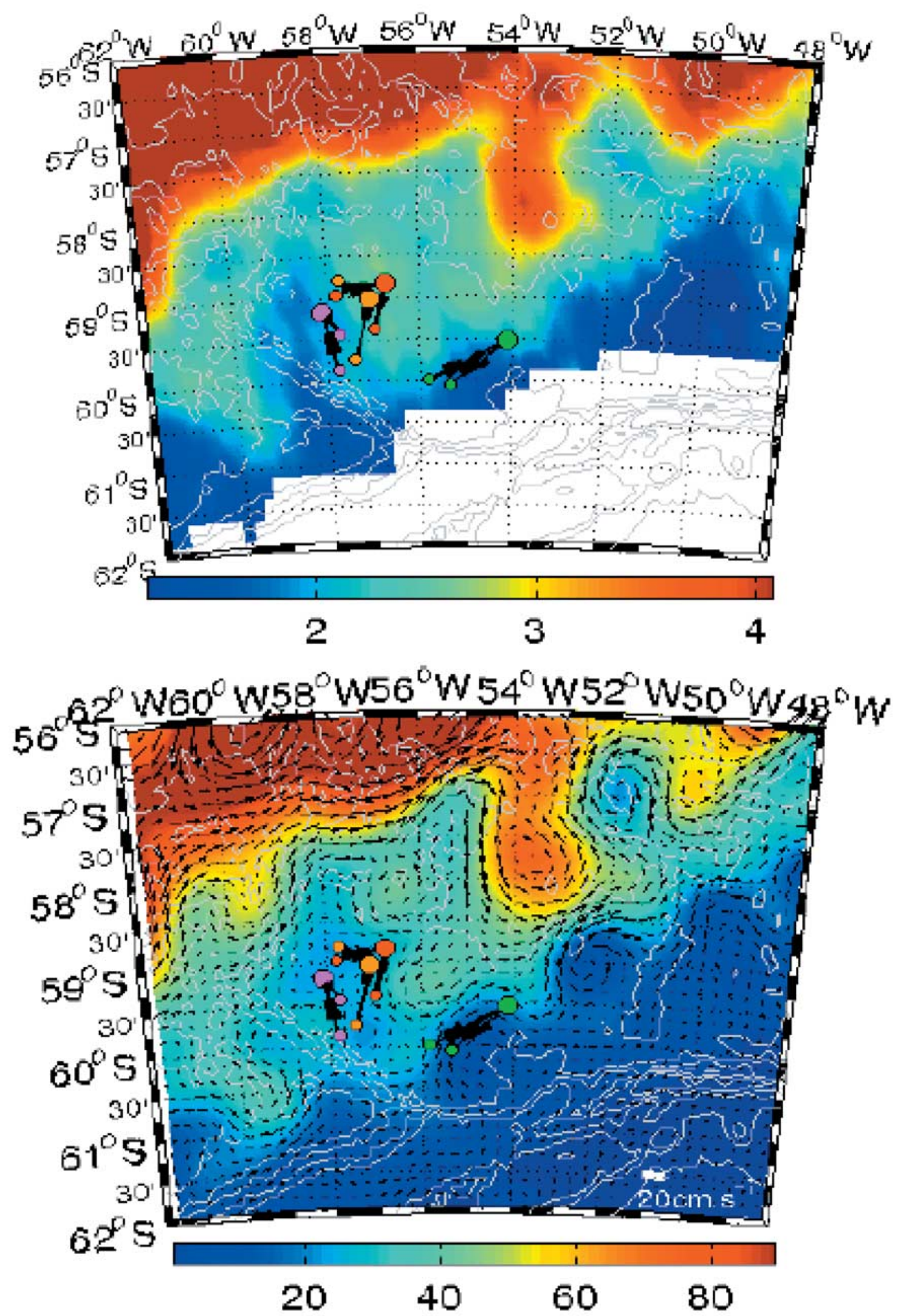

Figure 5b. (top) AMSR-E SST (in ${ }^{\circ} \mathrm{C}$ ). (bottom) Sea surface height in $10^{-2} \mathrm{~m}$ and surface geostrophic velocity obtained from SLA and a Mean Sea [Rio et al., 2005] (scale of velocity to the lower right corner). 

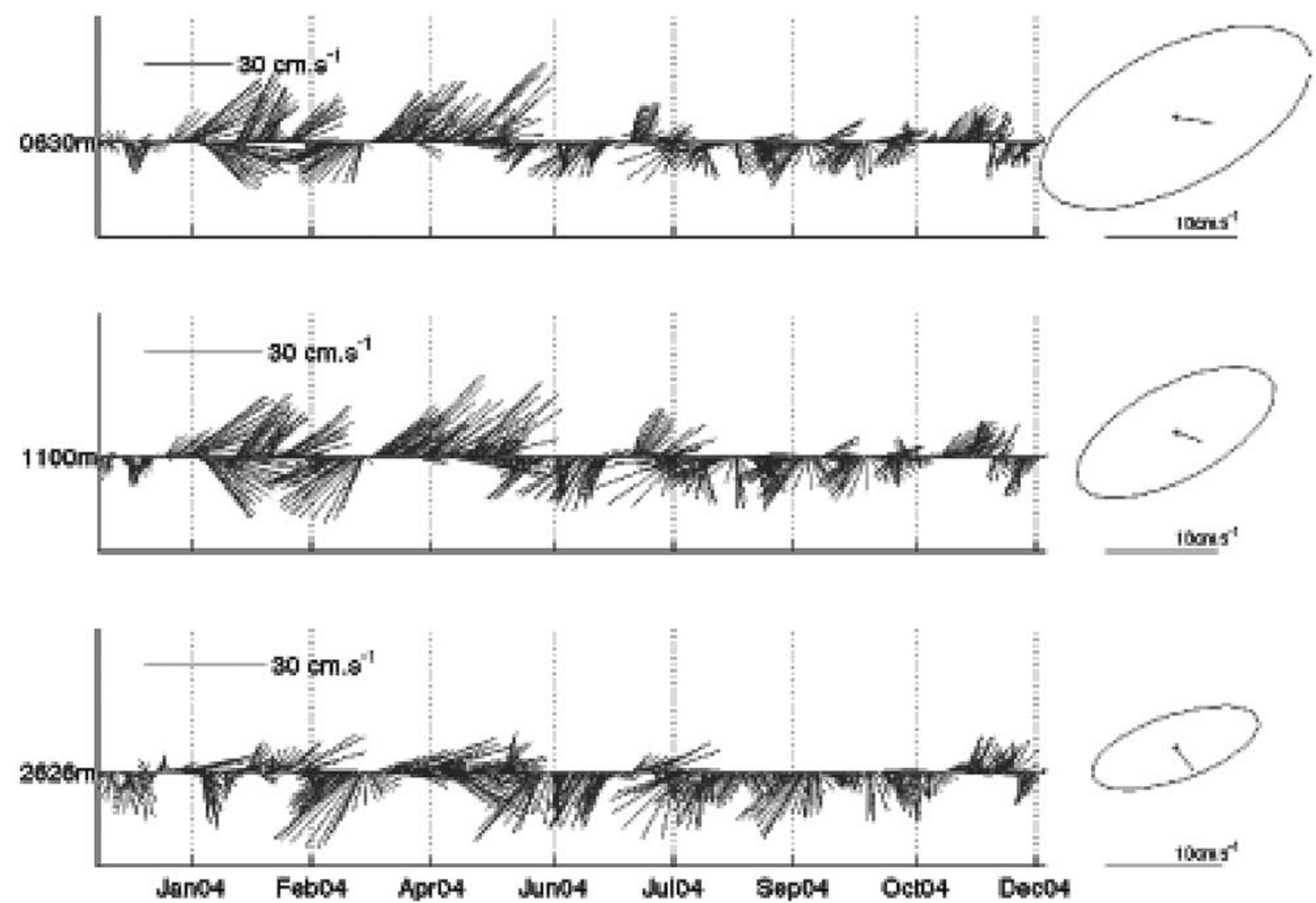

Figure 6. Stickplots of the velocities from the current meter mooring at $60^{\circ} 37^{\prime} \mathrm{S}$ and $53^{\circ} 50.5^{\prime} \mathrm{W}$. All data are low-pass filtered with a resampling interval of $12 \mathrm{~h}$. (top) Current meter RCM8 at $630 \mathrm{~m}$, (middle) current meter RCM11 at $1100 \mathrm{~m}$, and (bottom) current meter RCM11 at $2626 \mathrm{~m}$. Mean and variance ellipses to the right of each stickplot.

WW in summer, and of WW, in winter. The SACCF is associated with an isopycnal tilt (therefore a geostrophic current) and, in terms of $\theta-\mathrm{S}$, it can be identified with the southern boundary of the UCDW, reaching $1.8^{\circ} \mathrm{C}$ or $\sigma_{\theta} \sim$ $27.70 \mathrm{at} 500 \mathrm{db}$. Thus the profiles with $\sigma_{\theta}$ between 27.6 and 27.7 are considered to lie to the north of the SACCF and to the south of the PF (green dots in Figure 8a), and those with $\sigma_{\theta}$ between 27.7 and 27.75 are considered to lie to the south of the SACCF and to the north of the SBdy (red dots). Figure 8a suggests that the SACCF branches and is variable in location.

[24] Exceptionally clear MODIS images permitted the identification of the location of fronts in the Ona Basin in January 2005 (Figure 5a). The Polar Front (with a strong SST gradient, limited by the $3.7^{\circ} \mathrm{C}$ isotherm, and with a very low chlorophyll $a$ concentration) follows the southern side of the West Scotia Ridge and makes a huge southward meander centered on $58^{\circ} \mathrm{S}$ and $54^{\circ} \mathrm{W}$. The SACCF (identified by a low chlorophyll $a$ concentration and a simultaneous SST of about $2.25^{\circ} \mathrm{C}$ ) appeared to branch over the SFZ: one branch joining the PF at $58^{\circ} \mathrm{S}$, another branch terminating in a mushroom-like eddy, in the area where the three northern floats were located, and a third branch meandering over the Shackleton Fracture Zone, passing finally through the Shackleton Gap (a deep but narrow gap, at a depth of at least $3000 \mathrm{~m}$, between the SFZ and the continental slope at $57^{\circ} \mathrm{W}$ (Figure 1) and meandering eastward. At $53^{\circ} \mathrm{W}$, the southern branch was extremely close to the southern limit of the PF meander $\left(59^{\circ} \mathrm{S}\right)$. The SBdy location was more speculative; it corresponded probably to the northern boundary of the region of high chlorophyll $a$ concentration to the south, and to a temperature of less than $1^{\circ} \mathrm{C}$.

[25] Three floats $(5900476,3900195$, and 3900197, shown in magenta, red and orange symbols in Figures 5a and $5 \mathrm{~b}$ ) were located between the two branches of the SACCF and entrained within a cyclonic circulation. The fourth float (3900196, in green) also had a cyclonic circulation and was located in a region where the southern branch of SACCF and the SBdy were close to each other. Corresponding $\theta-\mathrm{S}$ diagrams (Figure $8 \mathrm{~b}$ ) contain some $\mathrm{CDW}$, showing that the profiles were all located to the north of the SBdy. A number of cold and fresh intrusions were observed in the proximity of the salinity maximum. They are indicative of interleaving entrainment of UCDW with WDW. The float displacements corresponded to mean velocities, at $2000 \mathrm{db}$, of between 05 and $14 \mathrm{~cm} \mathrm{~s}^{-1}$. Thus intense mesoscale activity was present together with intrusions along isopycnal surfaces $\left(27.7<\sigma_{\theta}<27.8\right)$. These intrusions were not observed over deep waters on the 
Table 2. Statistics of Currentmeter Measurements in $2004^{\mathrm{a}}$

\begin{tabular}{|c|c|c|c|c|}
\hline & Time Series & $630 \mathrm{~m}$ & $1100 \mathrm{~m}$ & $2626 \mathrm{~m}$ \\
\hline $\bar{P}$, dbar & whole time series & 514 & 1003 & 2596 \\
\hline \multirow[t]{2}{*}{$\sigma_{\mathrm{P}}, \mathrm{dbar}$} & whole time series & 60.3 & 55.5 & 6.2 \\
\hline & whole time series & 0.66 & 0.75 & -0.051 \\
\hline \multirow[t]{3}{*}{$\bar{T},{ }^{\circ} \mathrm{C}$} & summer & 0.84 & 0.80 & -0.055 \\
\hline & winter & 0.50 & 0.72 & -0.056 \\
\hline & whole time series & 0.56 & 0.20 & 0.032 \\
\hline \multirow[t]{3}{*}{$\sigma_{\mathrm{T}},{ }^{\circ} \mathrm{C}$} & summer & 0.51 & 0.16 & 0.030 \\
\hline & winter & 0.59 & 0.21 & 0.025 \\
\hline & whole time series & 2.8 & 4.6 & 4.0 \\
\hline \multirow{2}{*}{$\|\bar{V}\|, \mathrm{cm} \mathrm{s}^{-1}$} & summer & 5.8 & 4.6 & 4.4 \\
\hline & winter & 2.5 & 2.5 & 4.1 \\
\hline \multirow[t]{3}{*}{$\arg (\bar{V}), \operatorname{deg}$} & whole time series & 102 & 116 & 157 \\
\hline & summer & 76 & 86 & 141 \\
\hline & winter & 173 & 176 & 174 \\
\hline \multirow{3}{*}{$\|V\|_{\max }, \mathrm{cm} \mathrm{s}^{-1}$} & summer & 41.5 & 30.5 & 30.1 \\
\hline & winter & 23.2 & 23.3 & 21.2 \\
\hline & whole time series & 12.3 & 10.5 & 9.2 \\
\hline \multirow[t]{3}{*}{$\overline{\|V\|}, \mathrm{cm} \mathrm{s}^{-1}$} & summer & 15.2 & 13.0 & 10.8 \\
\hline & winter & 10.4 & 8.8 & 8.2 \\
\hline & whole time series & 7.3 & 6.0 & 5.1 \\
\hline \multirow{2}{*}{$\sigma_{\overline{\|V\|}}, \mathrm{cm} \mathrm{s}^{-1}$} & summer & 8.6 & 6.6 & 5.7 \\
\hline & winter & 4.4 & 4.3 & 4.2 \\
\hline
\end{tabular}

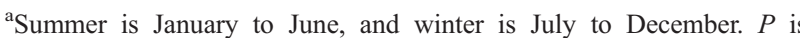
pressure, $T$ is in situ temperature, $V$ is the velocity (after 3-d low-pass filtering), and $\sigma$ denotes the standard deviation. Overbar indicates a time average over the record length. Here $\arg (\bar{V})$ is the mean velocity direction (positive values are clockwise relative to the geographical north), $\|\bar{V}\|$ is the modulus of the time-averaged velocity, $\overline{\|V\|}$ is the average of the velocity modulus, and $\rho_{v}^{2}$ is the vector correlation coefficient (perfect correlation $\left.\rho_{v}{ }^{2}=2\right) ; \rho_{v}{ }^{2}$ is equal to 1.85 between data at $630 \mathrm{~m}$ and $1100 \mathrm{~m}$, and equal to 1.18 between data at $1100 \mathrm{~m}$ and $2626 \mathrm{~m}$.

western side of the SFZ. Float 3900196, the only float that managed to cross the SFZ, provided seven profiles in the deep water east of the SFZ, but there were no signs of intrusions on the corresponding $\theta-\mathrm{S}$ diagram, in contrast to the profiles to the west of the SFZ in the Ona Basin (Figure 8c).

\subsection{Spatial Distribution of Properties}

[26] Maps of properties obtained by kriging (Figure 9) were not synoptic and should be interpreted with care, since they reflect both time and space variations. At all depths, they exhibited a patchy distribution of properties in the center of the Ona Basin, with the denser water to the southeast corresponding to water from the Weddell-Scotia Confluence and lighter water to the northeast corresponding to profiles north of the Polar Front.

[27] As winter mixed-layer depth often exceeded $100 \mathrm{~m}$, temperature distribution at $100 \mathrm{db}$ was seasonally aliased, being WW in winter and ASW in summer. At $100 \mathrm{db}$, the density distribution mimicked the salinity distribution; here, the salinity controls density, hence the stratification in the upper layer. Salinities higher than 34.2 corresponded to water from the WSC. The $100 \mathrm{db}$ maps suggested that patches of dense water from the south managed to penetrate quite far north into the Ona Basin.

[28] At $500 \mathrm{db}$, temperature controls density; to the southeast, the denser water corresponded to water from the WSC which was colder, less saline and denser than CDW (mixture of CDW, Weddell Seawater and Antarctic Peninsula shelf water). In the center of the Basin, both UCDW and LCDW were present, with a patchy distribution, the saltier spots corresponding to LCDW. The mesoscale structures seen at $500 \mathrm{db}$ were consistently observed throughout the water column down to $2000 \mathrm{db}$. Most correspond to water patches from the south, although the one near $59^{\circ} 30^{\prime} \mathrm{S}$ and $53^{\circ} 30^{\prime} \mathrm{W}$ was of water from the north. The consistency in the vertical suggested that the salinity accuracy was probably better than the nominal 0.02 . The patches in salinity, temperature and density corresponded to deeply penetrating mesoscale structures.

\subsection{Winter in the Ona Basin}

[29] The float data covered five winters (2002 to 2006) and presented an exceptional concentration of profiles (float 3900196 ) over the shelf break at $57^{\circ} \mathrm{W}$ and $61^{\circ} \mathrm{S}$, just to the southwest of the Shackleton Gap (Figure 4). They provided a welcome documentation of the WW ventilation. Profiles of temperature and salinity plotted as a function of $\sigma_{\theta}$ were particularly illustrative (Figure 10). Ventilation down to a $\sigma_{\theta}$ of about 27.4 corresponded to WW formation or ventilation. The surface ASW $\left(\sigma_{\theta}<27.25\right)$ disappeared in May or June and reappeared in December (Figures 10a and 10b). As noted in section 3.1, ASW salinity is lower than that of WW. Ventilation to deeper levels occurred in the WSC and along the shelf south of the SBdy (for example, cycle 20 and 74 to 79 for float 3900195, Figure 10a, and cycles 23 to 28 for float 3900196, Figure 10b).

[30] Float 3900196 documented the winter conditions on the slope from 12 July to 10 September 2004. It provided a sequence of five profiles (profiles 23 to 27) nearly at the same location (the distance between profiles 23 and 27 was $29 \mathrm{~km}$ ) (Figure 11). The float remained between the 1900 and $1000 \mathrm{~m}$ isobaths and could not dive to its $2000-\mathrm{db}$ parking depth. The float was probably stuck on the seafloor between two successive profiles, and thus its drift was inhibited. The successive profiles indeed suggested that advection was probably much stronger than the float trajectory indicated. The rather surprising change in surface density between cycles 23 and 24, from near 27.2 to 27.54 , associated with a strong salinity increase (from 33.82 to $34.15)$ and a slight warming $\left(-1.35\right.$ to $\left.-1{ }^{\circ} \mathrm{C}\right)$ corresponded to a change from cold WW to saltier shelf water (Figures $10 \mathrm{~b}$ and 11). Cycles 24 and 26 did not present intrusions and were typical shelf-water profiles, whereas cycles 23,25 and 27 showed warm and salty intrusions at depth. These intrusions were of different magnitude, vertical extent and at different $\sigma_{\theta}$ levels. They suggested an intense isopycnal mixing between shelf waters and UCDW along the $\sigma_{\theta} 27.7$ surface (cycle 27) and between Weddell Deep Water and LCDW along the $\sigma_{\theta} 27.8$ surface (Figure 11). These processes typical of the Weddell-Scotia Confluence [Whitworth et al., 1994] were thus also found along the continental slope. After cycle 27, the float was caught up in a strong burst of current associated with the southern branch of the SACCF passing through the Shackleton Gap, and reentered the Ona Basin at a velocity of approximately $20 \mathrm{~cm} \mathrm{~s}^{-1}$ at $2000 \mathrm{db}$.

\section{Circulation and Eddy Activity in the Ona Basin in 2002-2006}

\subsection{From Argo Floats at About 2000 db}

[31] Float 3900195 spent its first 22 cycles near the SFZ (blue part of the trajectory in Figure 3a) during which it was 

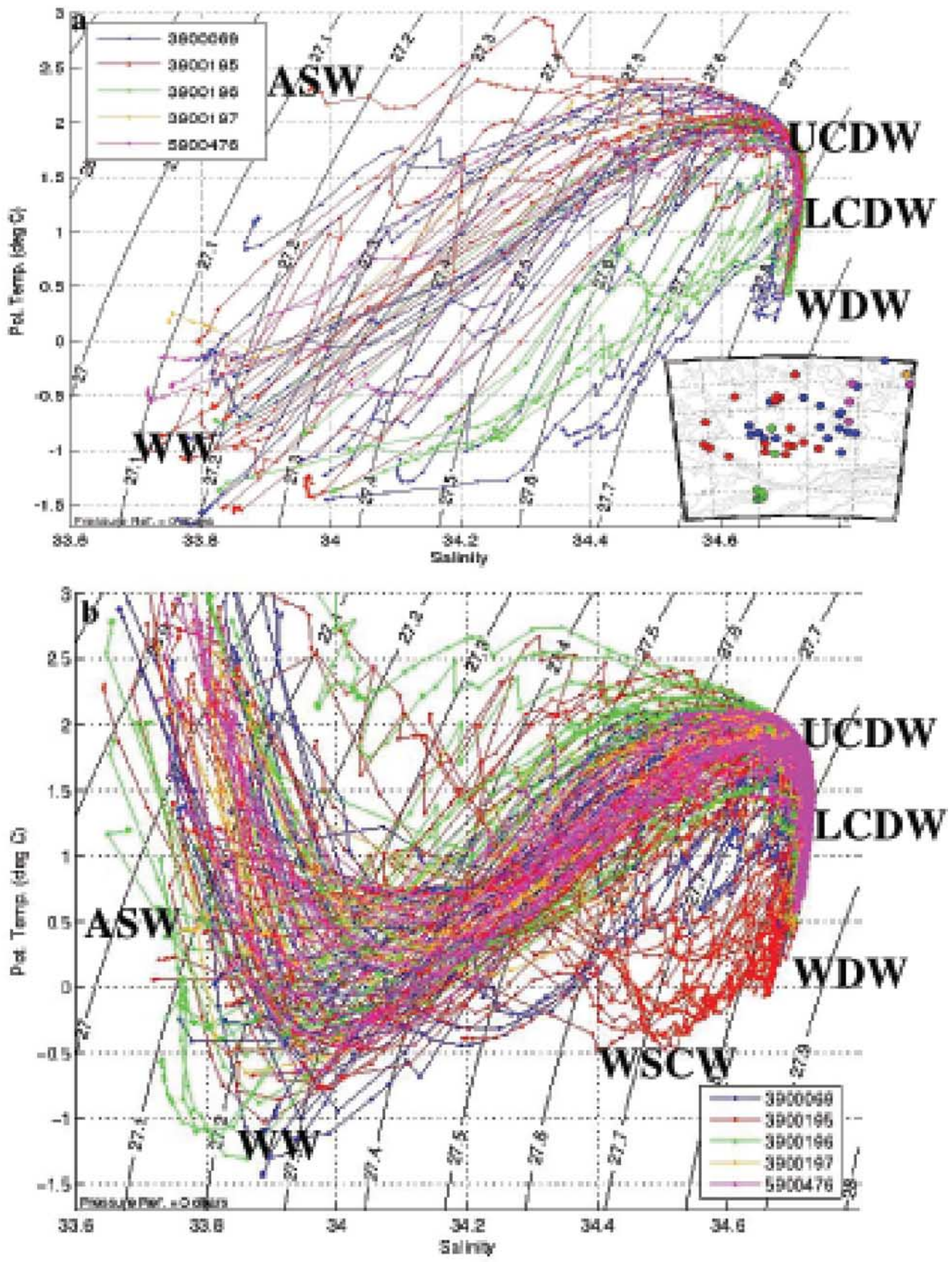

Figure 7 

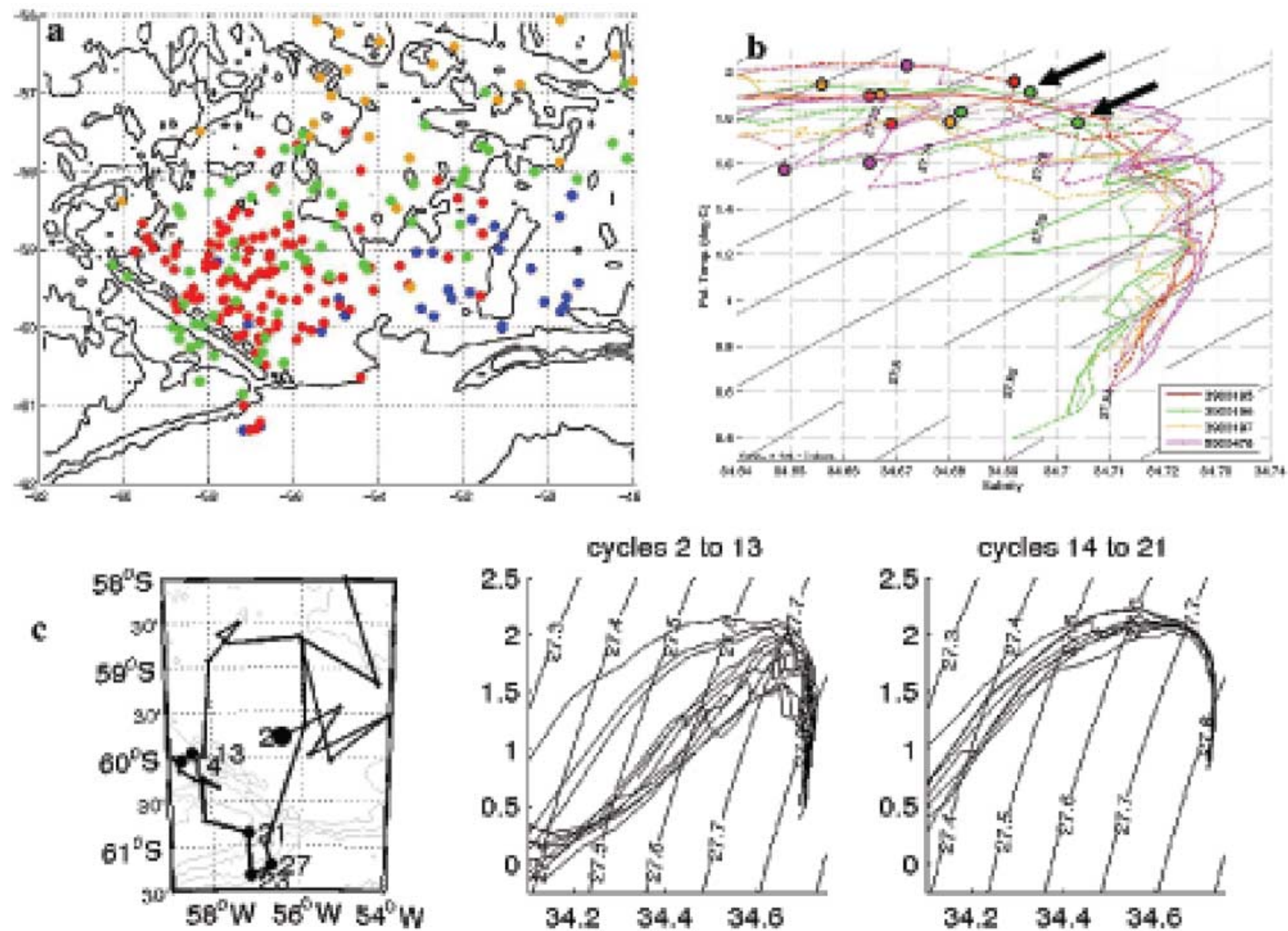

cycles 2 to 13

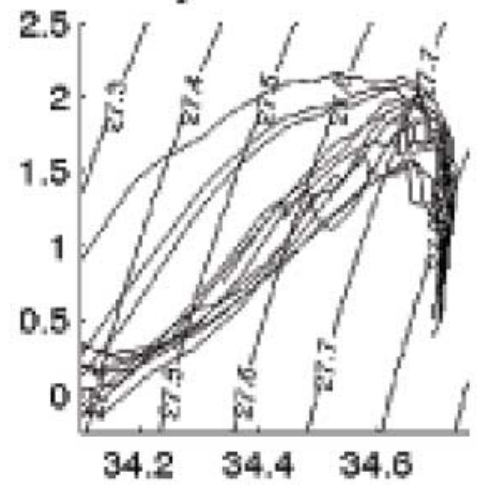

cycles 14 to 21

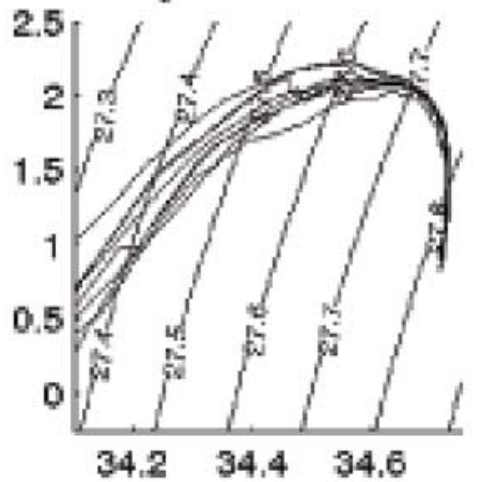

Figure 8. (a) Profile positions with respect to the fronts. Blue dots are locations of profiles with a potential density greater than 27.74 at $500 \mathrm{db}$, therefore profiles obtained to the south of the SBd; orange dots are profiles to the north of the PF $\left(\sigma_{\theta}<27.6\right.$ at $\left.500 \mathrm{db}\right)$; green dots are profiles between the PF and the SACCF $\left(27.6<\sigma_{\theta}<27.70\right)$; red dots are water between the SACCF and the SBdy $\left(27.7<\sigma_{\theta}<\right.$ 27.74). (b) Deep part of the $\theta$-S diagrams from profiles corresponding to the floats in Figure 6. Large dots are $\theta$-S values at $500 \mathrm{db}$; the two arrows point to $\theta$-S values on either side of the SBdy. (c) (left) Part of the trajectory of float 3900196, (middle) $\theta$-S diagram from cycles 2-13 (deep waters to the east of the SFZ), and (right) $\theta$-S diagram from cycles 14-21 (deep waters to the west of the SFZ).

carried in a cyclonic eddy (cycles 8 to 11 ) with cold and low-salinity water, spent one cycle (cycle 18) south of the SBdy, and had 10-d mean velocities less than $13 \mathrm{~cm} \mathrm{~s}^{-1}$ (Figure 12). Then it completed four cyclonic loops of various sizes in the basin (green and pink parts of the trajectory) from cycles 20 to 72 ; i.e., July 2004 to November 2005. Ten-day mean velocities reaching $18 \mathrm{~cm}$ $\mathrm{s}^{-1}$ were then observed. One profile over the WSR was to the north of the PF (cycle 26). Cycles 72 to 84 (yellow part of the trajectory in Figure 3a) corresponded to a drift around the Shackleton Bank (SB) during spring 2005 and summer 2005-2006. There the float crossed the SACCF and the SBdy and water was colder, less salty and denser (Figure 3a). Ten-day mean velocities vary from close to zero to $14 \mathrm{~cm} \mathrm{~s}^{-1}$ (Figure 12). Then, from cycle 84 on, the float crossed the PF (warmer, less salty and lighter water) and exited the Ona Basin.

[32] Float 3900196 managed to cross the SFZ at $58.5^{\circ} \mathrm{W}$ and $60^{\circ} \mathrm{S}$ in early April 2004. Absolute surface-topography maps and SST images provided consistently similar ocean

Figure 7. Two $\theta$-S diagrams. (a) A $\theta$-S diagram from winter profiles (July, August, September, October); five winters were sampled. Main water masses are indicated: WW, Winter Water; UCDW, Upper Circumpolar Deep Water; LCDW, Lower Circumpolar Deep Water; WDW, Warm Deep Water; WSCW, Water from the Weddell-Scotia Confluence. Profiles with surface salinities higher than 34.3 are located to the south of the SBdy. (b) A $\theta$-S diagram from the profiles of the five floats, except for the winter-season profiles, shown above. Main water masses are: ASW, Antarctic Surface Water; WW, Winter Water; UCDW, Upper Circumpolar Deep Water; LCDW, Lower Circumpolar Deep Water; WDW, Warm Deep Water; WSCW, Water from the Weddell-Scotia Confluence. 

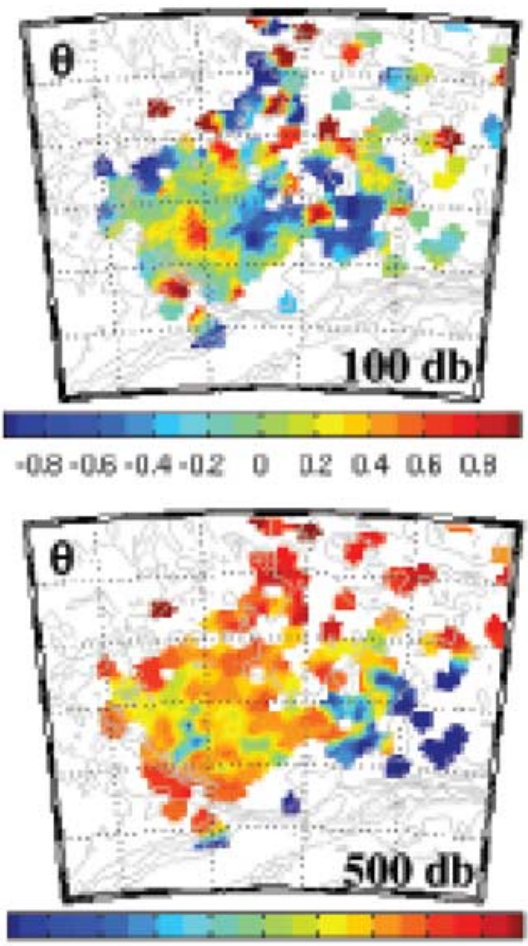

$\begin{array}{llllllllll}0.7 & 0.9 & 1.1 & 1.9 & 1.5 & 1.7 & 1.9 & 2.1 & 2.3\end{array}$
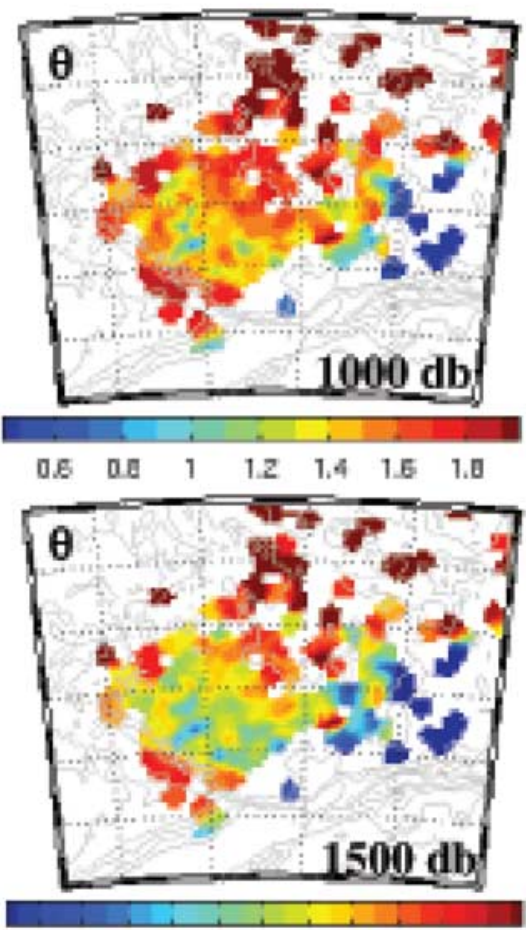

O.S 0.E 0.7 0.0 0.9 1 1.11 .21 .31 .41 .5
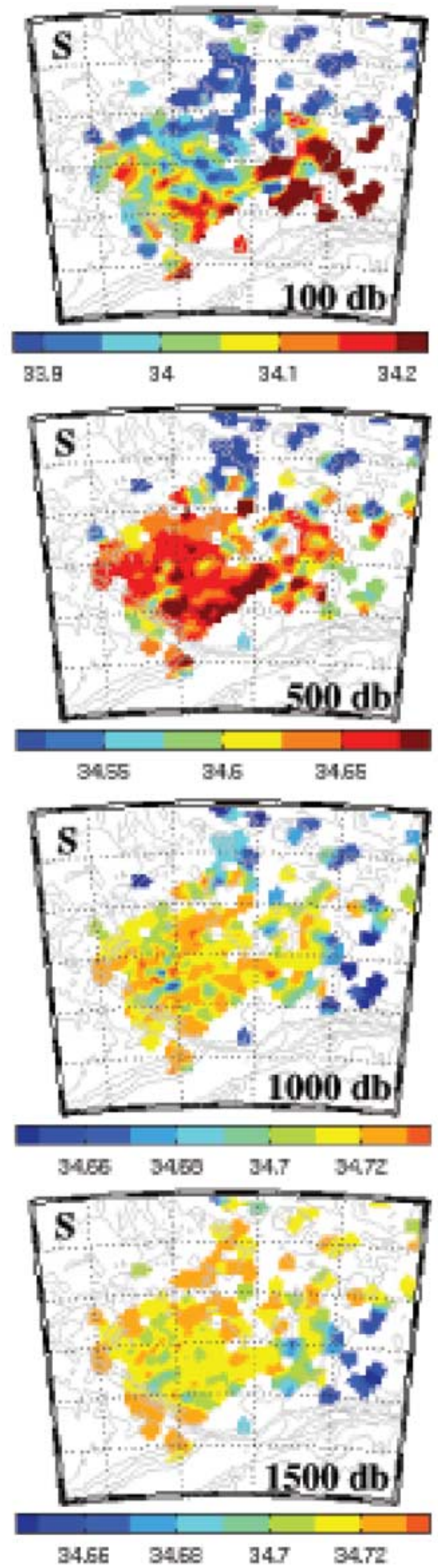
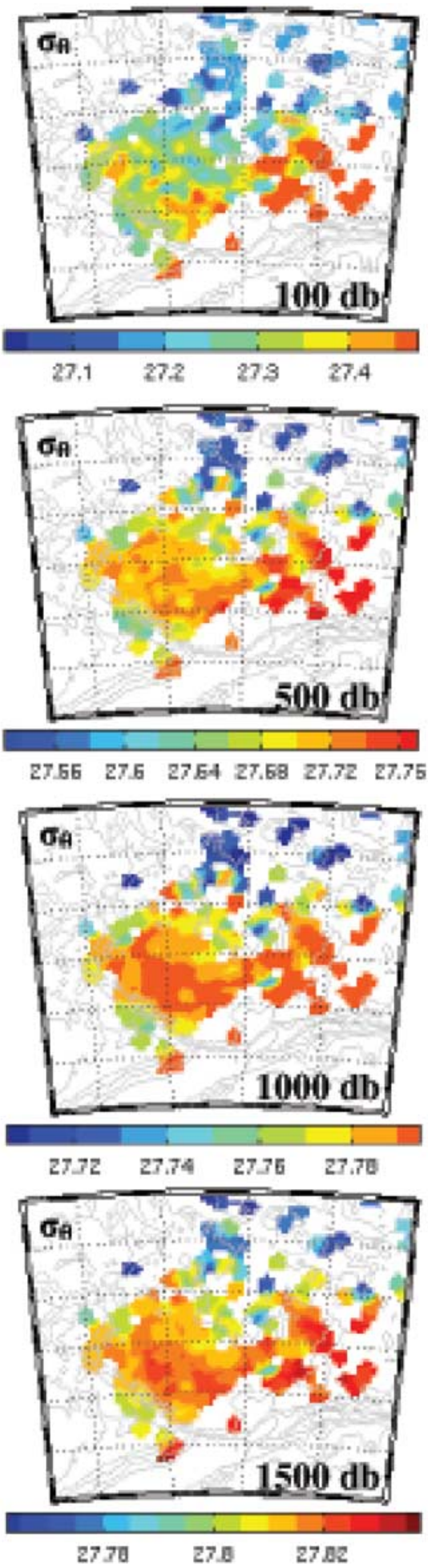

Figure 9. Two-dimensional maps of (left) potential temperature, (middle) salinity, and (right) $\sigma_{\theta}$ at (first row) $100 \mathrm{db}$, (second row) $500 \mathrm{db}$, (third row) $1000 \mathrm{db}$, and (bottom) $1500 \mathrm{db}$.

structures in terms of the meanders and eddies present (Figure 13). They suggested that the float was taken into a westward-drifting warm eddy that got trapped for $100 \mathrm{~d}$ over the SFZ (cycles 12 to 22). The float profiles during those cycles indicated waters with ACC characteristics (those between the PF and the SACCF) (Figure 3b). The float spent almost half a year ( 16 cycles) on the western side of the SFZ. It remained close to the SFZ during autumn 2004. In June 2004 it drifted farther south and got stuck along the continental slope during winter 2004 (see section 3.4). Ten-day mean drift velocities were small on the western side of the SFZ (2.5 $\mathrm{cm} \mathrm{s}^{-1}$ maximum). The float 


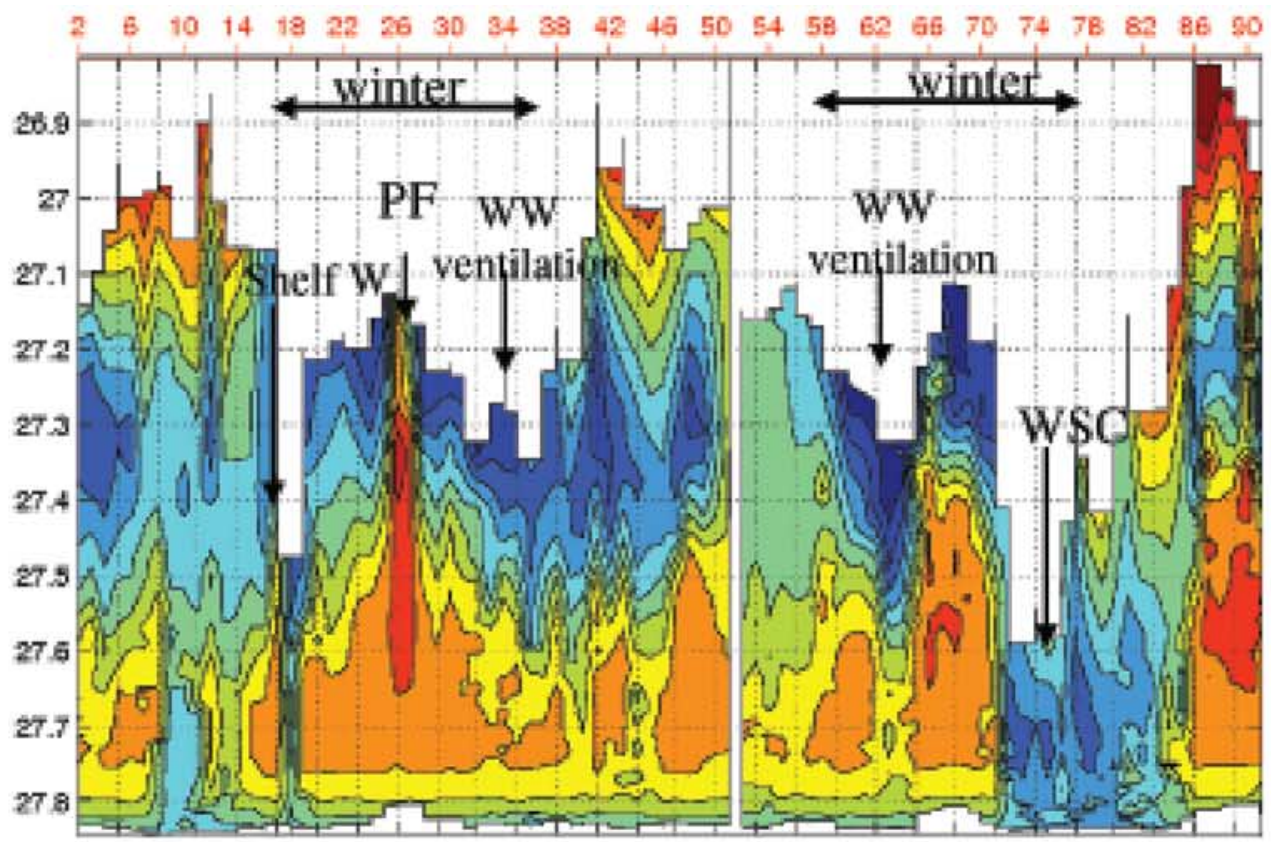

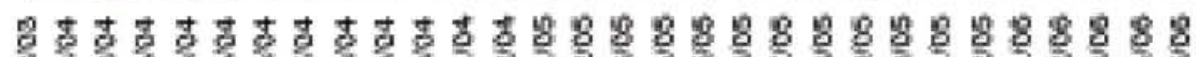

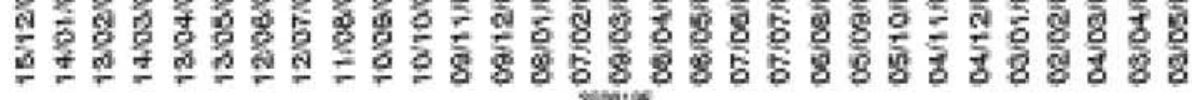

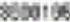
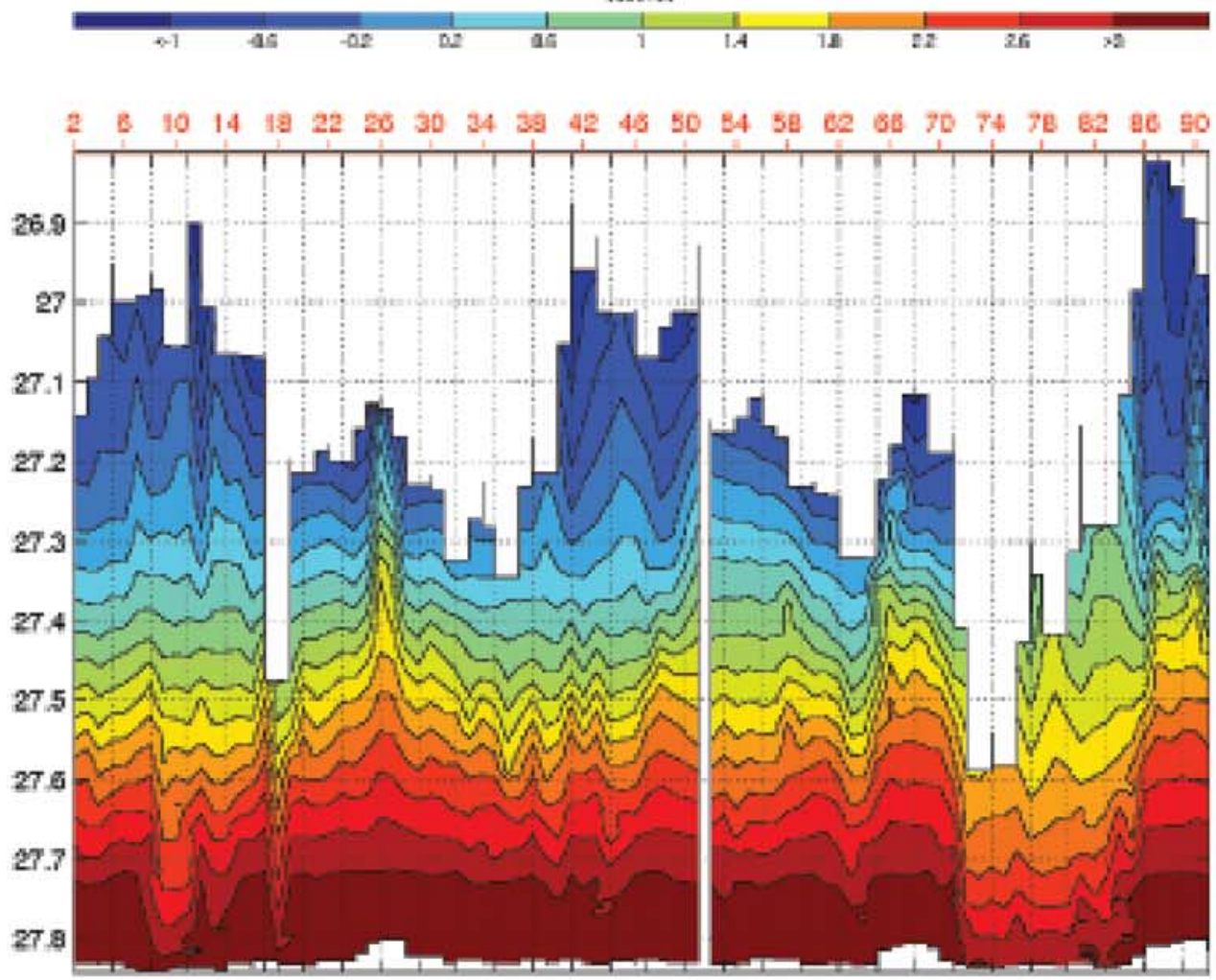

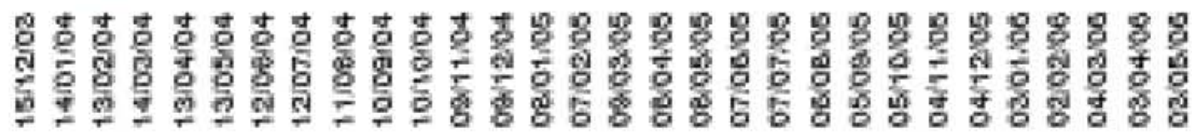

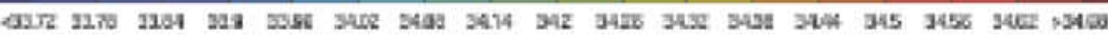

Figure 10a. Float 3900195. (top) Profiles of potential temperature and (bottom) salinity as a function of time; the vertical axis is the potential density. 

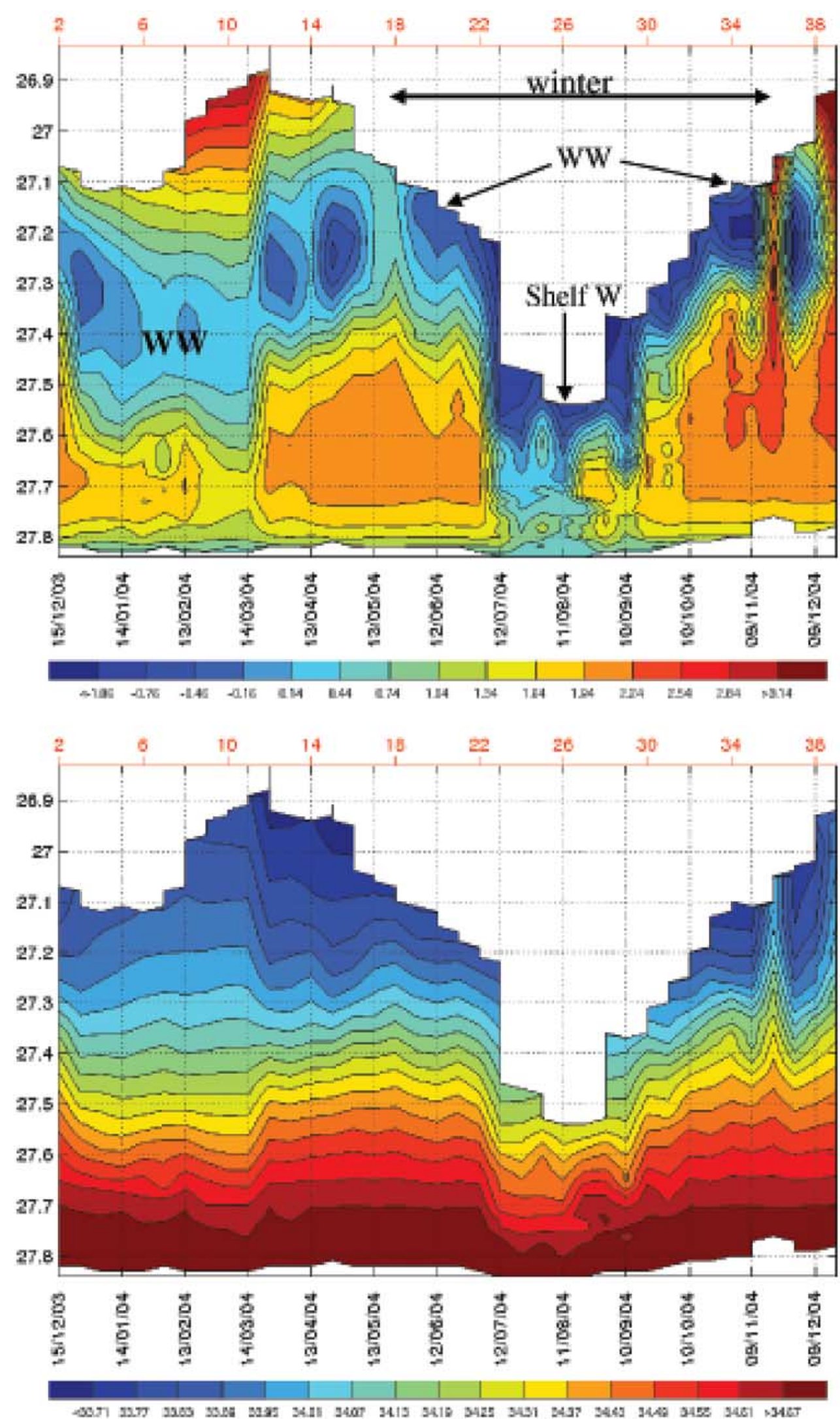

Figure 10b. Float 3900196. (top) Profiles of potential temperature and (bottom) salinity as a function of time; the vertical axis is the potential density. 


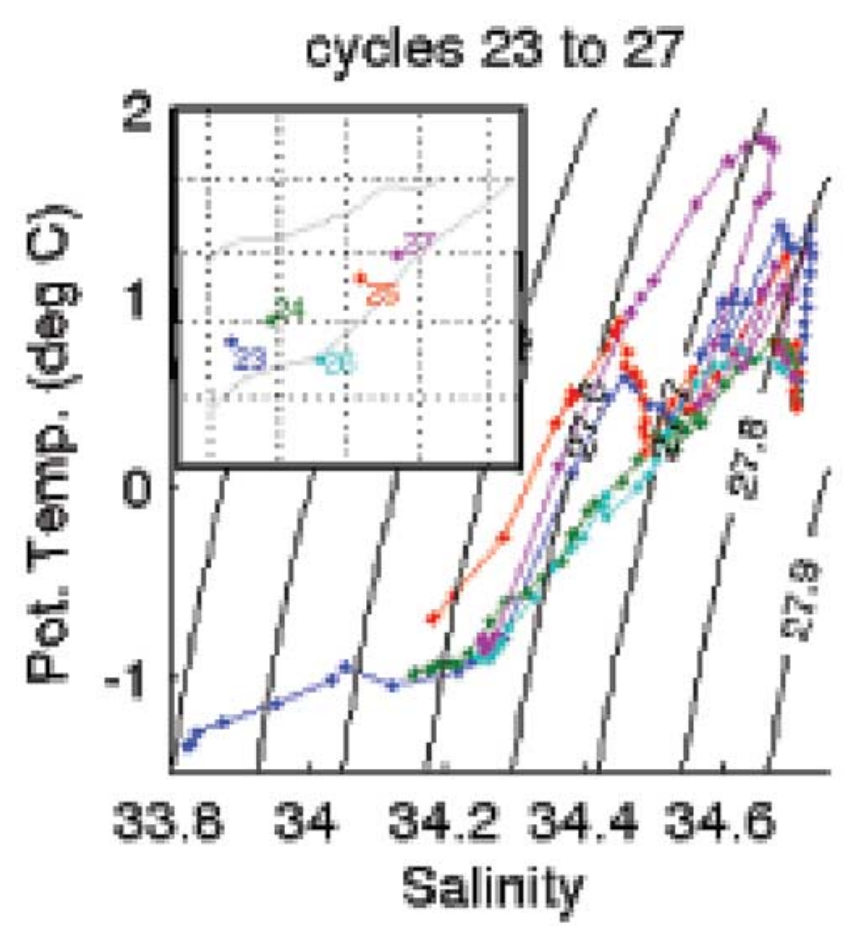

Figure 11. The $\theta-\mathrm{S}$ diagrams from winter profiles (cycles 23-27) near the shelf to the south of the SFZ (float 3900196). Profile 27 was obtained just before the float went through the Shackleton Gap entrained by the southern branch of the SACCF at a velocity close to $0.2 \mathrm{~m} \mathrm{~s}^{-1}$.

finally moved rapidly through the Shackleton Gap (SG) (close to $20 \mathrm{~cm} \mathrm{~s}^{-1}$ ) into the Ona Basin and exited the Basin to the north shortly after crossing the PF at cycle 36 .

[33] Float 3900069 followed a clockwise drift around the Ona Basin for eight months (June 2002 to January 2003) with $10-\mathrm{d}$ mean velocities reaching up to $18 \mathrm{~cm} \mathrm{~s}^{-1}$ (Figure 12). On its way it got trapped to the east of the $\mathrm{SB}\left(53^{\circ} \mathrm{W}\right.$, $59.5^{\circ} \mathrm{S}$ ) between the SBdy and the SACCF for two months (mid-September to mid-November 2002) (10-d mean velocities about $\left.6 \mathrm{~cm} \mathrm{~s}^{-1}\right)$. Then, it moved westward to its deployment location, and remained blocked between the SFZ and the center of the basin for six months. Drift velocities were low when the float was close to the SFZ $\left(2-12 \mathrm{~cm} \mathrm{~s}^{-1}\right)$ and increased up to $18 \mathrm{~cm} \mathrm{~s}^{-1}$ when the float moved eastward. It exited the basin to the northeast, drifting around the Ona Basin seafloor depression (OSD).

[34] Float 3900197 stayed five months (14/12/03 to $12 /$ 05/04) between the SFZ and the OSD with small velocities (the highest was $12.5 \mathrm{~cm} \mathrm{~s}^{-1}$ ). Then it exited the Ona Basin following the SACCF.

[35] Float 5900476 spent seven and a half months in the Basin, with no particular trajectory, except that it seemed to drift around the southern side of the OSD before exiting.

[36] Thus, float trajectories indicated a general clockwise circulation around the Ona Basin with $10-\mathrm{d}$ mean velocities ranging from 2 to $20 \mathrm{~cm} \mathrm{~s}^{-1}$ at $2000 \mathrm{db}$ (Figure 12). At $2000 \mathrm{db}$, the SFZ acts as a barrier. The accumulation of float profiles (Figure 4) to the east of the SFZ $\left(57^{\circ} \mathrm{W}, 59.5^{\circ} \mathrm{S}\right)$ corresponded to the region where 10-d mean drift velocities were usually small $\left(2-9 \mathrm{~cm} \mathrm{~s}^{-1}\right)$. Most of the floats showed high velocities $\left(10-20 \mathrm{~cm} \mathrm{~s}^{-1}\right)$ in the vicinity of the OSD. Two profilers (3900069 and 3900195 ) remained more than three months near the SB in the WSC (spring 2002 for 3900069 and middle of spring 2005 to middle of summer 2006 for 3900195). Potential density at all depths was higher in the center of the Basin and was surrounded by lower values (except to the south), which is indicative of a cyclonic circulation (Figure 9).

[37] We do not want to over interpret the long-time trajectories which can be biased by surface processes during data transmission. This is why we focused on the four floats showing the shortest time at the surface.

\subsection{From Satellite Data}

[38] Mean surface geostrophic current and variance ellipses were computed from maps of absolute dynamic topography (MADT) (see section 2.3) for the time period of the float trapping (2002-2006). The mean flow suggested a general eastward flow, generally strong in the north and much weaker in the south, and bore no indication of westward flow near the continental slope (Figure 14). It also showed an imprint of a deflection over the SFZ and a region of negligible mean flow in the Ona Basin, just to the east of the SFZ. A small mean westward flow was observed between $59^{\circ} 30^{\prime}$ and $60^{\circ} \mathrm{S}$ over the SFZ. This quiescent region is a result of the SFZ acting as a barrier to the SACCF. Just to the north of the OSD, near $57.5^{\circ} \mathrm{S}$ and $53.5^{\circ} \mathrm{W}$, the mean flow was weak, whereas it was stronger over the OSD. Variance ellipses for the geostrophic currents should be examined with caution as the time sampling (7 d) may not resolve important timescales of the variability of the surface flow. We also computed the ellipses for nearreal-time data with a 3.5-d resolution; there was no difference. The 3.5-d resolution was mainly an interpolation; the limitation is due to the satellite sampling. Variance ellipses were large in the north and over the OSD; they were much weaker in the south.

[39] Why did the floats remain such a long time in the Ona Basin when the mean front locations in the Basin [from Orsi et al., 1995] suggested a general eastward pathway with the Antarctic Circumpolar Current (Figure 1) and when there was no evidence of a westward flow near the continental slope? Most floats spent quite a long time in the quiescent region, but the region was not as quiescent as the altimetry suggested, since 10-d mean float drifts at $2000 \mathrm{db}$ ranged between 3 and $13 \mathrm{~cm} \mathrm{~s}^{-1}$ (Figure 12). Satellite images, such as those in Figure 5b, provided some hint. The warm meander centered at $58^{\circ} \mathrm{S}$ and $54^{\circ} \mathrm{W}$ in Figure $5 \mathrm{~b}$ corresponded to a standard deviation in the SLA of $\sim 15 \mathrm{~cm}$. The meander was located over a 200-km-diameter depression (at a depth of $4500-5000 \mathrm{~m}$ ) in the bottom topography (OSD in Figure 1). Annual mean SSTs in 2003, 2004 and 2005 also showed the warm meander at the same location (not shown). The meander may have played a role in trapping the floats in various ways. First, the meander often shed warm eddies propagating westward, as can be observed in Figure 13. These eddies have hydrographic characteristics of waters between SAF and PF. Their characteristics become progressively eroded as they move westsouthwest. They often terminate their course on the SFZ. These eddies are a major source of westward motion. Second, the meander deflects float trajectories southward: 

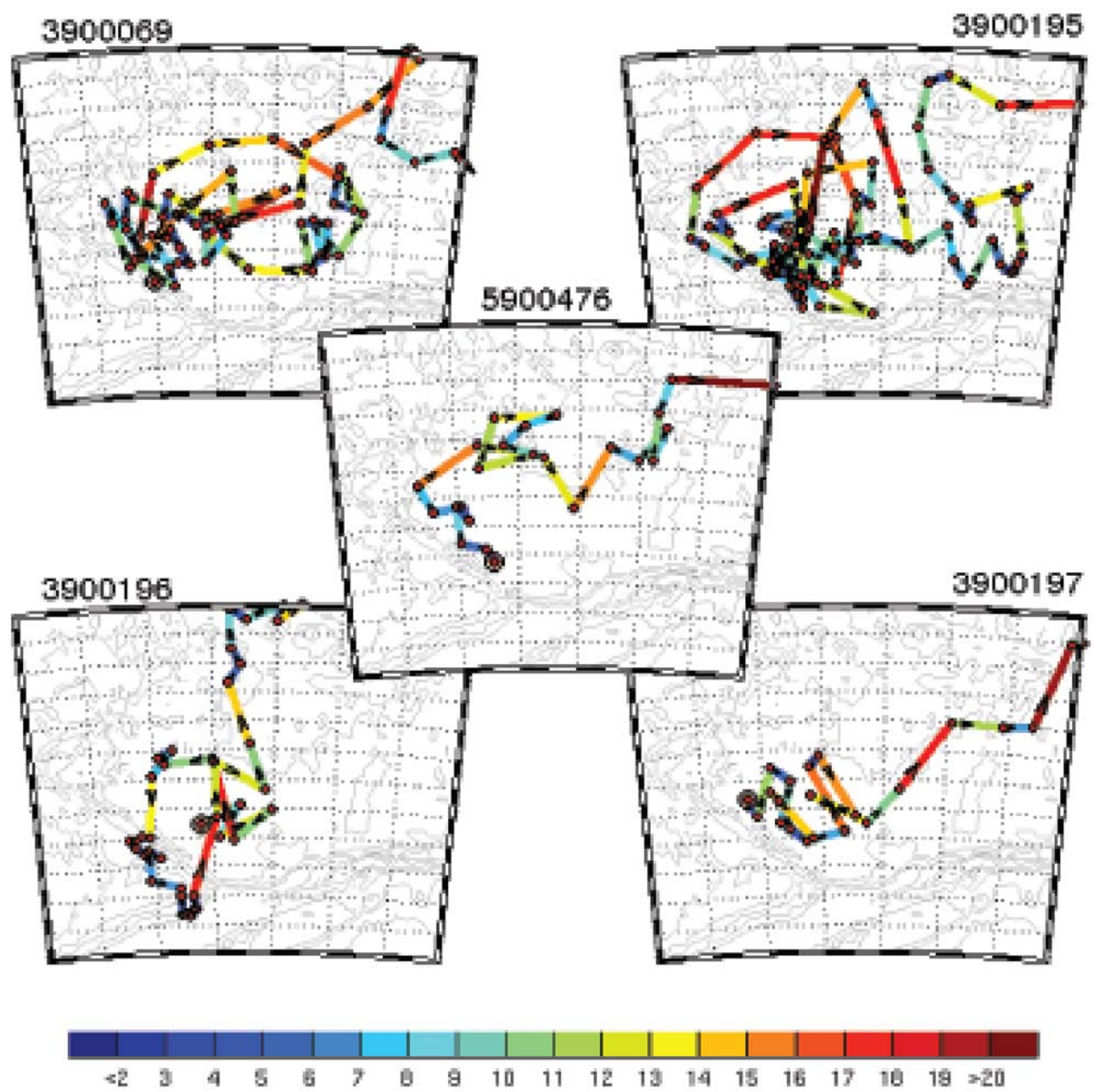

Figure 12. Ten-day mean velocities at the 2000-db parking depth.

float 3900195 got pushed back three times by the meander before it could exit. Only one float (3900196) exited on the northwestern side of OSD. As will be seen in Figure 15a, it was at a time, December 2004, with no meander over the OSD. All the other floats had to go around the OSD at the meander periphery before exiting the Ona Basin.

[40] The warm meander is not, of course, the whole story. Cold eddies appear to detach from meanders along the continental slope and move north, as suggested by properties typical of waters south of the SBdy observed near $59^{\circ} \mathrm{S}$ and $58^{\circ} \mathrm{W}$ (Figure 7a). They are more difficult to examine because of the limitations of the satellite data south of $59^{\circ} \mathrm{S}$, as discussed in section 2.3. As shown by the water proper- ties observed by the floats, all the eddies, whether cyclonic or anticyclonic, were deep-penetrating eddies.

\subsection{From Current Meter Data}

[41] The annual mean velocities are weak, less than $5 \mathrm{~cm} \mathrm{~s}^{-1}$ with an eastward-southeastward component at all depths (Figure 6 and Table 2). This is consistent with float observations, which do not show any evidence of westward flow near the continental slope. The mean surface geostrophic velocities from Rio et al. [2005] also suggest an eastward velocity at the mooring location (Figure 14). In contrast to the altimetry-derived surface velocities, current meter velocities have a large variability and mean values smaller than the standard deviation (Figure 6 and Table 2). 

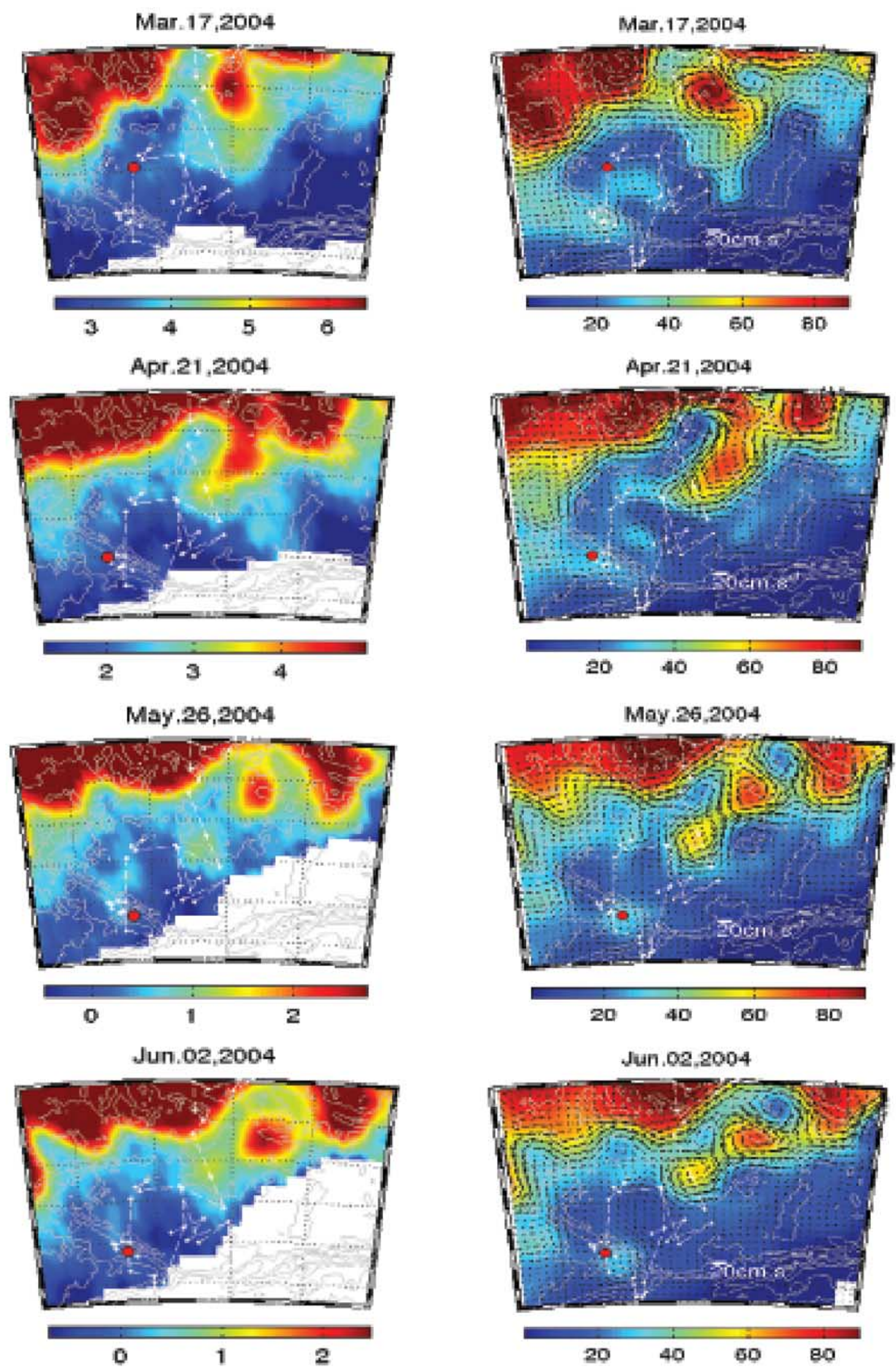

Figure 13 


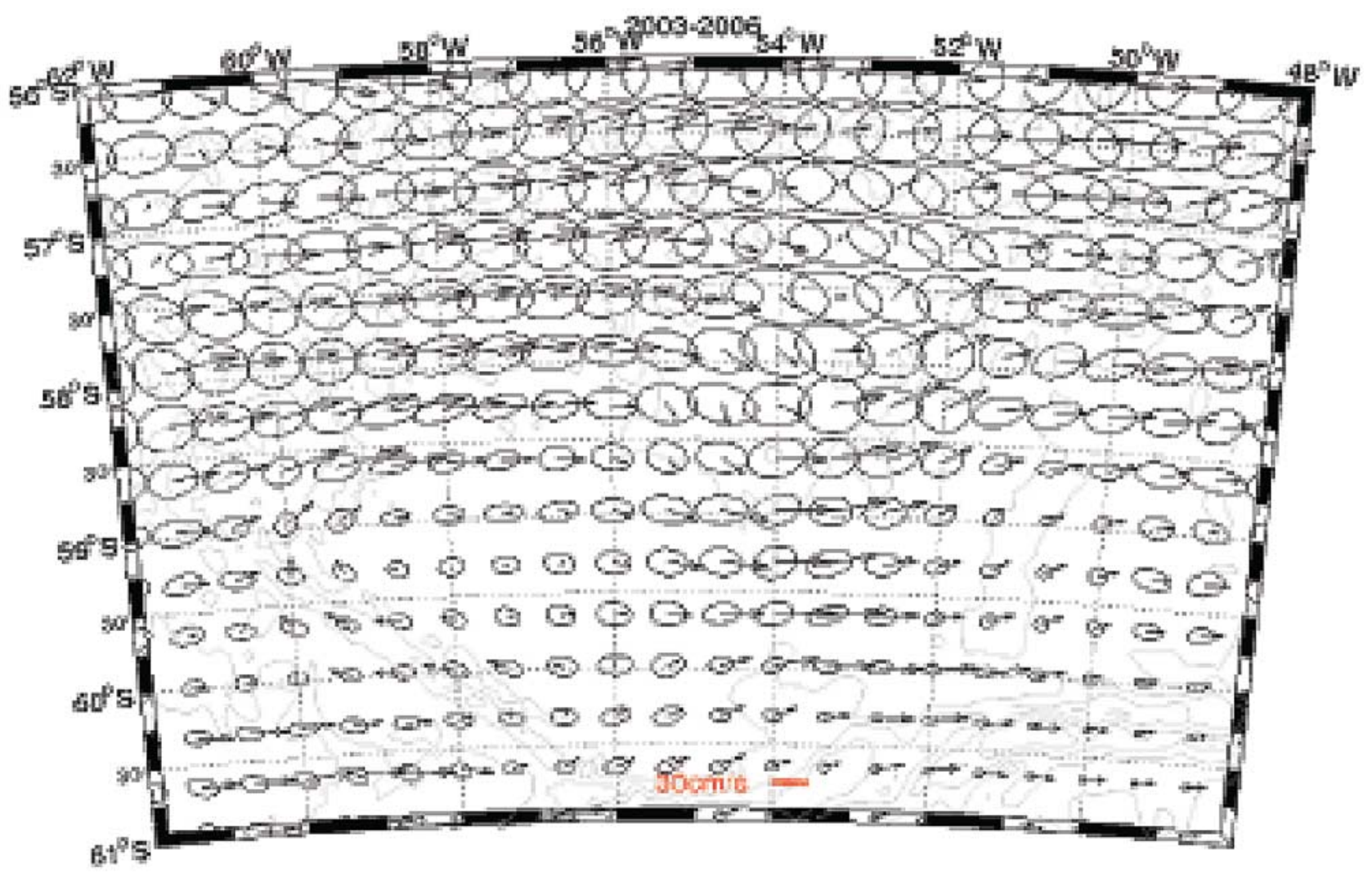

Figure 14. Variance ellipses for surface geostrophic velocities and mean surface geostrophic velocities during the period of the float trapping (2002-2006); the surface geostrophic velocities were derived from maps of dynamic topography provided by AVISO.

At the 3 depths, velocities exceeded $30 \mathrm{~cm} \mathrm{~s}^{-1}$ during bursts. Velocity amplitudes were stronger in summer than in winter (Figure 6 and Table 2), possibly because of ice cover in winter. Decorrelation timescales are about twenty days at the three levels for each component.

[42] The rotation of the stick plots is indicative of the meandering of the SACCF southern branch and of mostly cyclonic eddies passing by. The coherence is large in the vertical: vector correlation coefficients, $\rho_{\mathrm{v}}^{2}$ [Crosby et al., 1993], are above 1 (Table 2) thus indicative of a vertically coherent variability. This is the result of the deep-reaching SACCF and eddy activity.

\section{Float Period in an Altimetric Perspective}

[43] Were the oceanographic conditions in 2002-2006 exceptional? SST and SLA time series from location $\left(54^{\circ} \mathrm{W}\right.$, $58^{\circ} \mathrm{W}$ ) corresponding to the center of the meander identified above were similar over their common period (August 2002 to December 2006), once the seasonal cycle was removed from the SST time series (not shown). The meander had a warm SST anomaly in excess of $1{ }^{\circ} \mathrm{C}$ on average for the period 2003-2005, corresponding to an SLA of $15 \mathrm{~cm}$. During most of the float period (March 2002 to April 2006), the meander was present.

[44] The 14-year-long SLA time series (1992-2006) changed sign intermittently until 2002, and became positive from 2002 to April 2006 (Figure 15a). Since April 2006, it has been negative. The time series spectrum has a significant ( $95 \%$ confidence limits) peak at $120 \mathrm{~d}$ (not shown). As anticipated in the section above, in December 2004 when float 3900196 exited the Ona Basin, the meander was absent (not shown).

[45] We perform a regression analysis of the SLA field in the Drake Passage onto the SLA time series at the meander location. The statistical significance is inferred by testing the correlation using a 2-sided Student t-test. This analysis (Figure 15b) shows that the variability of the SLA over the OSD is strongly correlated with the variability in the Yaghan Basin (YB). The pattern in YB is dipolar with a variability of roughly $\pm 5 \mathrm{~cm}$ and is statistically significant at the $5 \%$ level (as inferred by the statistical test on the correlation). The variability in the Drake Passage seems to be linked to the topographic features: in the YB the centers

Figure 13. Distribution of (left) sea surface temperature and (right) sea surface height with surface geostrophic velocities at various dates, corresponding to float 3900196 crossing the SFZ westward. SST from AMSR-E is in ${ }^{\circ} \mathrm{C}, \mathrm{SSH}$ is in $10^{-2} \mathrm{~m}$. The scale of the geostrophic surface velocity vectors is in the lower right-hand corner. The white dotted line is the float trajectory. The red dot is the float surface location at the time of the SST or SSH. 

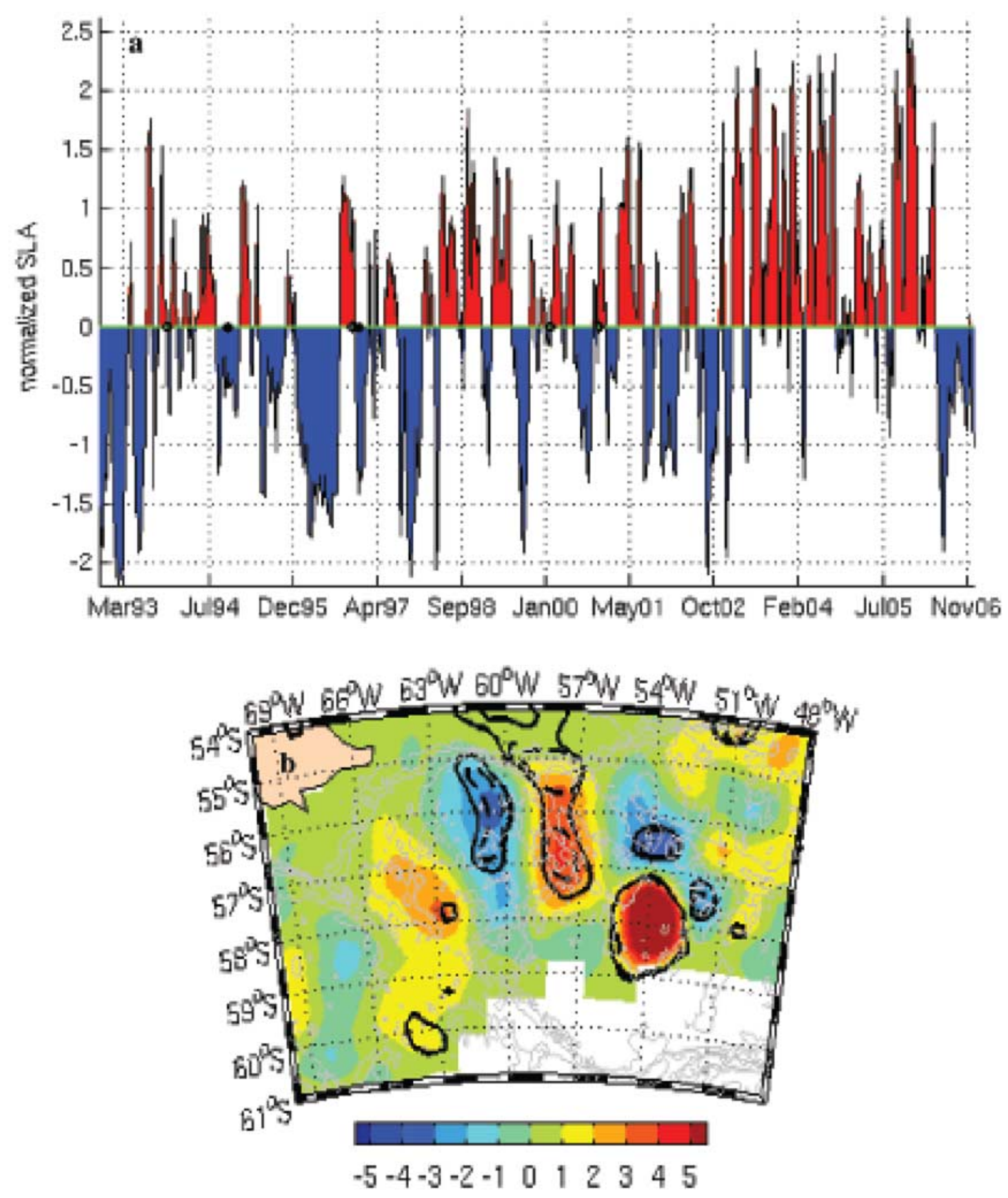

Figure 15. (a) Normalized time series of SLA at $54^{\circ} \mathrm{W}, 58^{\circ} \mathrm{S}$ (averaged over a 1 -degree $\times 1$-degree box). (b) regression of SLA at Drake Passage on the normalized time series in Figure 15a. Bold line is correlation at the $90 \%$ confidence level; dashed line is correlation at the $97.5 \%$ confidence level.

of the dipole are located respectively over the shallowest and deepest part of the basin (YSD).

[46] We then used an EOF analysis of SLA over the Drake Passage to seek modes that would correspond to the patterns highlighted by the regression analysis. More than 60 EOFs are needed to represent $90 \%$ of the total variance. The first four EOFs account for respectively 8.4\%, 6.5\%, $5.7 \%$ and $5.3 \%$ and the spatial structures (not shown) are clearly degenerated. The EOF analysis is a very efficient tool to compress the complicated variability of SLA into a few temporally independent components (PC), but the associated patterns (EOFs) do not systematically represent modes or processes of the physical system since the spatial orthogonality of the patterns imposes a severe limitation. Using the varimax method to relax the spatial orthogonality constraint, we obtained rotated empirical orthogonal functions (R-EOF) producing more coherent structures [Horel, 1981]. The first three R-EOFs are more localized in space than the standard EOF modes and represent $6.5 \%, 4.3 \%$ and $3.8 \%$ of the variance. The third R-EOF (Figure 16) exhibits spatial patterns similar to those on the regression map. However, the varimax rotation imposes to have more free 


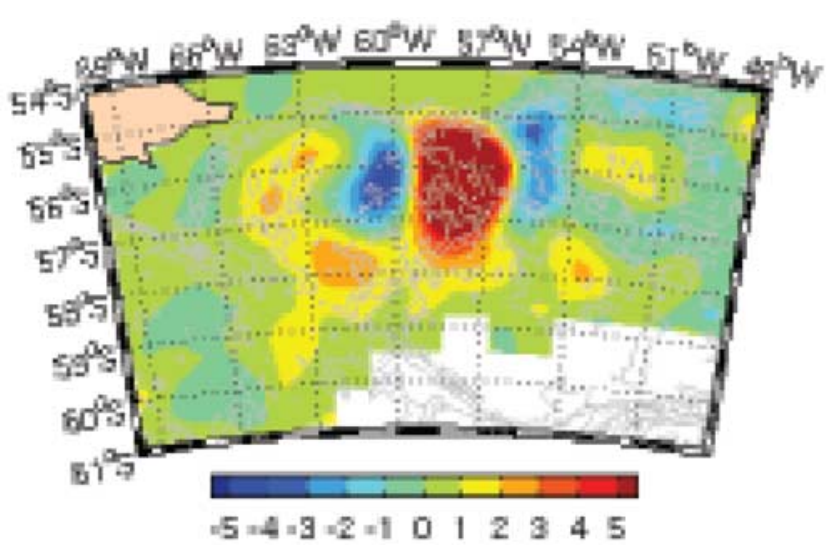

Figure 16. Using the varimax method to release the spatial orthogonality constraint, we obtained rotated empirical orthogonal functions (R-EOF). Spatial pattern of R-EOF 3 (in centimeters) exhibits spatial patterns similar to those on the regression map.

parameters, thus explaining why the percentage of explained variance is small. We also need to keep in mind that the percentage of represented variance is no longer additive since the new patterns and coefficients (time series) are not orthogonal and uncorrelated at the same time [von Storch and Zwiers, 1999]. In order to assess the consistency of these three modes, we varied the number of EOFs retained before rotation. We used 80 EOFs (which correspond to a cumulative percentage of variance between of 93.5\%), 85 EOFs (94.2\%) and 90 EOFs (94.8\%). The three experiments exhibited the same first three spatial patterns after rotation (R-EOFs). Such a strong reproducibility of the patterns shows that they are robust, far different from noise. Thus, the use of two different statistical methods (Rotated EOF and regression analysis with statistical significance level) points out to the same direction: the variability over the Ona Seafloor Depression appears to be associated with basin-trapped modes of SLA in the Yaghan Basin.

[47] As an illustration of the circulation associated with this "mode," we add and remove ones the pattern of R-EOF3 to the mean dynamic topography of Rio et al. [2005] (Figure 17). It is then more obvious that R-EOF3 characterizes the formation of a southward meander of the SAF over the shallow part of the Yaghan Basin. In the presence of this meander, the SAF and PF meet at $58^{\circ} \mathrm{W}$ before separating downstream. It is interesting to note that the joining of the $\mathrm{SAF}$ and $\mathrm{PF}$ at $58^{\circ} \mathrm{W}$ and $58^{\circ} \mathrm{S}$ was observed during one hydrographic section along WOCE SR1 [Brandon et al., 2004]. Downstream, the SAF continues northward as the PF meanders around the OSD (Figure 17b). Under the opposite conditions, the SAF is only slightly shifted northward along SR1 and is then well separated from PF which does not meander around the OSD (Figure 17c).

\section{Discussion}

[48] The Ona Basin $\left(52-62^{\circ} \mathrm{W}, 57-61^{\circ} \mathrm{S}\right)$ is surrounded to the south by the Antarctic continental slope, to the north by the West Scotia Ridge (WSR), to the east by the Shackleton Bank and to the west by the Shackleton Fracture
Zone (SFZ) which constitutes the westernmost segment of the Scotia-Antarctic Plate boundary [Livermore et al., 2004] (Figure 1). Bathymetry exerts a strong constraint on the ACC in Drake Passage. First of all, the SACCF is strongly affected by the SFZ barrier. Part of the SACCF loops to the north rejoining the $\mathrm{PF}$ at $59^{\circ} \mathrm{S}$, where both these oceanographic features are steered east by the WSR; another part is deflected to the south and enters the Ona Basin through the Shackleton Gap; another part crosses the SFZ, becomes unstable and spawns eddies [Orsi et al., 1995; Sprintall, 2003; Amos, 2001]. The SACCF branching is difficult to observe by satellite. The SACCF does not have a clear signature in SST nor in altimetry. Altimetric data accuracy is limited in the south of the Drake Passage where geophysical correction models are less accurate, seasonal sea ice produces flagged data and the orbit angle can induce sampling problems at that latitude. A few clear ocean color images suggest that the meandering and branching of the SACCF along the SFZ is variable in time. We observed here that one float taken in an anticyclonic eddy managed to cross the SFZ toward the west.

[49] The Ona seafloor depression to the northwest of the Ona Basin is an important topographic feature with respect to the circulation, but to our knowledge it has not been discussed in previous literature. The five Argo floats trapped for a variable duration, from six months to two and a half years, in the Ona Basin, reflect a recirculation during that period (2002-2006). The presence of a PF meander over the OSD is probably an important element of the recirculation. The meander sheds anticyclonic westward-propagating deep-reaching eddies and deflects the trajectories of the floats toward the south.

[50] As shown by altimetry, the meander overlying the OSD is an intermittent feature, though present during the float period. An EOF analysis of SLA over Drake Passage identified one pattern of variability of the SSH in the Yaghan Basin that showed a positive signal over the OSD. This pattern is linked to the topography. It corresponds to a situation in which the SAF meanders southward over shallower topographic feature and joins the PF just two degrees to the west of the OSD.

[51] We did not find any evidence of westward flow near the continental slope in either the float or current meter data, in contrast to current pathway schemes proposed by von Glydenfelt et al. [2002] or Naveira Garabato et al. [2002a, 2002b].

[52] Floats got trapped in a westward-propagating eddy field. Most anticyclonic eddies escaped sooner or later from the OSD region. They were deep-reaching and carried water with characteristics typical of the region between the PF and SACCF. The meander over the OSD is a meander at the juncture of the PF and the northern branch of SACCF which joined the PF upstream at about $59^{\circ} \mathrm{S}$ and $57^{\circ} 30^{\prime} \mathrm{W}$ over the WSR. The northern branch of the SACCF may separate from the PF when eddies are shed over the OSD. Most of the anticyclonic eddies propagated westward until they reached the SFZ where they dissipated. A few were observed to return to the joined PF and SACCF over the WSR. Cyclonic eddies were either formed between the WSR and the path of the anticyclonic eddies or in the south of the Ona Basin. The cyclonic eddies were associated with velocities in excess of $30 \mathrm{~cm} \mathrm{~s}^{-1}$ in the current meter data. 

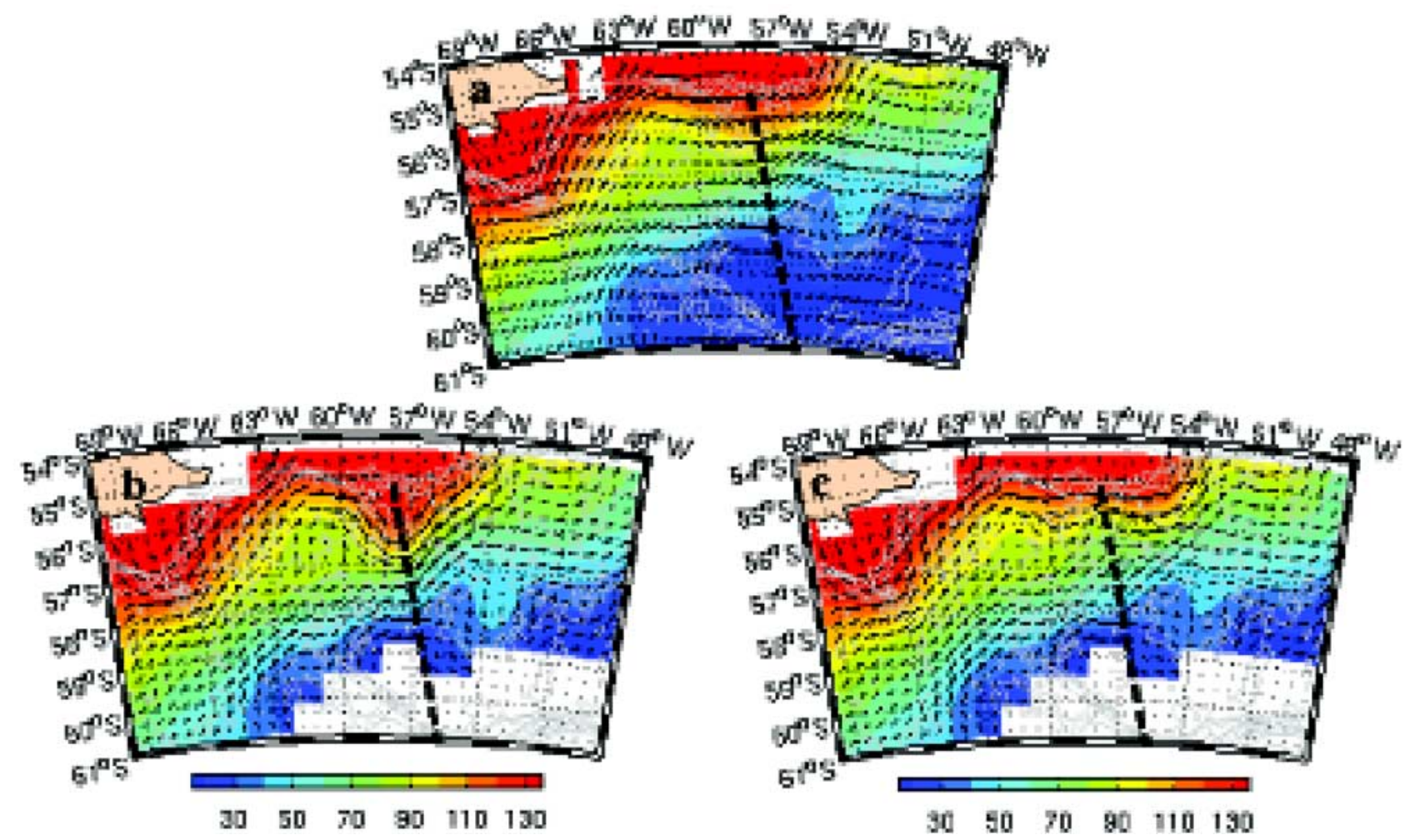

Figure 17. (a) Mean Dynamic Topography (MDT) of Rio et al. [2005] with superimposed geostrophic velocity vectors (in $\mathrm{cm} \mathrm{s}^{-1}$ ); (b) MDT adding ones the pattern of REOF-3; (c) MDT removing ones the pattern of REOF-3. Dashed line represents the WOCE SR1b section.

The intrusion of the SACCF southern branch onto the shelf generates cyclonic eddies pushing cold water off the shelf. This process is poorly documented because of the limitations of the satellite data in the south. Recently, Kahru et al. [2007] show that the eddies in the SACCF zone enhance biological production, the cyclonic eddies with high Chl-a concentration retain phytoplankton within the eddy cores and increase the light available for photosynthesis in the upper mixed layer whereas anticyclonic eddies have low Chl-a in the core but increased Chl-a in the periphery.

[53] East of the SFZ, within the Ona Basin, mesoscale eddies stir and stretch out scalar properties. Intrusions were observed at all levels in the water column. Strong interleaving in the pressure range $400-800 \mathrm{db}$ was associated with the disappearance of UCDW. Near the continental slope, interleaving was observed at all depths. The eddy stirring is an important path to the ultimate efficiency of mixing. Eddies may produce interleaving that leads to double diffusive convection, evidence of which is difficult to observe with the rather low vertical resolution of the float profiles. Dissipation of the eddies over topography or elsewhere and/or loss of geostrophic balance could produce mixing.

[54] Observations in the DP suggest that mixing is intense and widespread, even well above the rough bottom topography [Naveira Garabato et al., 2004, 2007]. Thompson et al. [2007], using data from an expendable-CTD repeated section, examined the spatial and temporal patterns of small-scale mixing in the DP to the west of the SFZ in the upper layer (from 100 to $1000 \mathrm{~m}$ ). They showed that the
Polar Front separates two dynamically different regions in terms of mixing. North of the PF, profiles are dominated by density-compensated interleaving, whereas strong interleaving is absent from the profiles from south of the PF. In contrast, in the Ona Basin, to the east of the SFZ, float data present strong interleaving due to the eddy stirring (Figure 7).

[55] Thus, Argo float data revealed the complex hydrography in the Ona Basin, with its wealth of intrusions. These data are a most valuable and adequate tool in that remote region. Dedicated floats with a higher vertical resolution would permit the computation of Thorpe scales and the estimation of vertical eddy diffusivity, as in work by Thompson et al. [2007]. Dedicated in situ measurements of the fine structure of the water column are necessary and would provide information on the processes that likely generate the ultimate mixing in the Ona Basin (for example, the breaking of internal waves on the sea bottom, whether of tidal or geostrophic origin, wind-induced inertial waves in the upper ocean etc.). Satellite data documented the complex dynamics in the Ona Basin and suggested some possible mechanisms. As noted earlier in the discussion section, present altimetric data accuracy is limited in the south of Drake Passage, however we believe that a specific method of processing the data in that area should help.

[56] New current meter moorings equipped with temperature and salinity sensors have been deployed recently in the Ona Basin to provide 2-year-long time series with small sampling intervals. These should bring quantitative information on the circulation and eddy fluxes. 
[57] Model output could be examined to study the variability of the branching of the SACCF and the potential role of the northern SACCF branch in the appearance of the OSD meander and eddy detachment. The variability of the ACC may influence the meandering of the SACCF along the SFZ and the eddy field present in the Ona Basin. For that, we need a model with high spatial resolution: the Shackleton Gap through which the southern branch of the SACCF goes at time is only $10 \mathrm{~km}$ wide.

[58] Acknowledgments. The float data were collected and made freely available by the International Argo Project and the national programs that contribute to it (http://www.argo.ucsd.edu, http://argo.jcommops.org). Argo is a pilot program of the IOC-WMO Global Ocean Observing System. Our gratitude goes to Ray C. Griffiths and to an anonymous reviewer for their valuable comments on the manuscript.

\section{References}

Amos, A. F. (2001), A decade of oceanographic variability in summertime near Elephant Island, Antarctica, J. Geophys. Res., 106, 22,401-22,423, doi:10.1029/2000JC000315.

Brandon, M. A., M. Naganobu, D. A. Demer, P. Chernyshkov, P. N. Trathan, S. E. Thorpe, T. Kamedaz, O. A. Berezhinskiy, E. J. Hawker, and S. Grant (2004), Physical oceanography in the Scotia Sea during the CCAMLR 2000 survey, austral summer 2000, Deep Sea Res., Part II, 51, 1301-1321, doi:10.1016/j.dsr.2004.06.006.

Bryden, H. L. (1979), Poleward heat flux and conversion of available potential energy in Drake Passage, J. Mar. Res., 37, 1-22.

Crosby, D. S., L. C. Breaker, and W. H. Gemmill (1993), A proposed definition for vector correlation in geophysics: Theory and application, J. Atmos. Oceanic Technol., 10, 355-367, doi:10.1175/1520-0426(1993) $010<0355$ :APDFVC $>2.0 . \mathrm{CO} ; 2$.

Cunningham, S. A., S. G. Alderson, B. A. King, and M. A. Brandon (2003), Transport and variability of the Antarctic Circumpolar Current in Drake Passage, J. Geophys. Res., 108(C5), 8084, doi:10.1029/ 2001JC001147.

Dong, S., J. Sprintall, and S. T. Gille (2006), Location of the Polar Front from AMSR-E Satellite Sea Surface Temperature Measurements, J. Phys. Oceanogr., 36, 2075-2089, doi:10.1175/JPO2973.1.

Gille, S. T. (2003a), Float observations of the Southern Ocean: Part I: Estimating mean fields, bottom velocities and topographic steering, J. Phys. Oceanogr., 33, 1167-1181, doi:10.1175/1520-0485(2003)033<1167: FOOTSO $>2.0 . \mathrm{CO} ; 2$.

Gille, S. T. (2003b), Float observations of the Southern Ocean: Part 2: Eddy fluxes, J. Phys. Oceanogr., 33, 1182-1196, doi:10.1175/1520-0485(2003) $033<1182$ :FOOTSO $>2.0 . \mathrm{CO} ; 2$.

Horel, J. D. (1981), A rotated principal component analysis of the interannual variability of the northern hemisphere $500 \mathrm{mb}$ height field, Mon. Weather Rev., 109, 2080-2092, doi:10.1175/1520-0493(1981) $109<2080$ :ARPCAO $>2.0 . \mathrm{CO} ; 2$.

Ichikawa, Y., Y. Takatsuki, K. Mizuno, N. Shikama, and K. Takeuchi (2002), Estimation of drifting velocity and error at parking depth for the Argo float, ARGO Tech. Rep. FY2001, pp. 68-77, Jpn. Agency for Mar.-Earth Sci. and Technol., Yokosuka, Japan.

Kahru, M., B. G. Mitchell, S. T. Gille, C. D. Hewes, and O. Holm-Hansen (2007), Eddies enhance biological production in the Weddell-Scotia Confluence of the Southern Ocean, Geophys. Res. Lett., 34, L14603, doi:10.1029/2007GL030430.

Lee, J. H. (2006), A study on the development of key elements for monitoring and prediction of the climate change (in Korean), Proj. Rep. BSPE 91700-1785-1, 385 pp., Korea Ocean Res. and Dev. Inst., Ansan, S. Korea.
Lee, J. H., S. T. Jang, C. S. Hong, S. C. Hwang, and C. Provost (2007), Observation of deep currents in the southern Drake Passage, EGU General Assembly 2007, Geophys. Res. Abstr., 9, 04854.

Le Traon, P. Y., Y. Faugère, F. Hernandez, J. Dorandeu, F. Mertz, and M. Ablain (2003), Can we merge GEOSAT Follow-On with TOPEX/Poseidon and ERS-2 for an improved description of the ocean circulation?, J. Atmos. Oceanic Technol., 20, 889-895, doi:10.1175/1520-0426(2003) $020<0889$ :CWMGFW>2.0.CO;2.

Livermore, R., G. Eagles, P. Morris, and A. Maldonaldo (2004), Shackleton Fracture Zone: No barrier to early circumpolar ocean circulation, Geology, 32, 9, 797-800, doi:10.1130/G20537.1.

Moore, J. K., M. R. Abbott, and J. G. Richman (1999), Location and dynamics of the Antarctic Polar Front from satellite sea surface temperature data, J. Geophys. Res., 104, 3059-3073.

Naveira Garabato, A. C., K. J. Heywood, and D. P. Stevens (2002a), Modification and pathways of Southern Ocean deep waters in the Scotia Sea, Deep Sea Res. Part I, 49, 681-705, doi:10.1016/S0967-0637(01) 00071-1.

Naveira Garabato, A. C., E. L. McDonagh, D. P. Stevens, K. J. Heywood, and R. J. Sanders (2002b), On the export of Antarctic Bottom Water from the Weddell Sea, Deep Sea Res., Part II, 49, 4715-4742, doi:10.1016/ S0967-0645(02)00156-X.

Naveira Garabato, A. C., K. L. Polzin, B. A. King, K. J. Heywood, and M. Visbeck (2004), Widespread intense turbulent mixing in the Southern Ocean, Science, 303(5655), 210-213, doi:10.1126/science.1090929.

Naveira Garabato, A. C., D. P. Stevens, A. J. Watson, and W. Roether (2007), Short circuiting of the overturning circulation in the Antarctic Circumpolar Current, Nature, 447, 194-197, doi:10.1038/nature05832.

Nowlin, W. D., Jr., T. Whitworth, and R. D. Pillsbury (1977), Structure and transport of the Antarctic Circumpolar Current at Drake Passage from short-term measurements, J. Phys. Oceanogr., 7, 788-810, doi:10.1175/ 1520-0485(1977)007<0788:SATOTA >2.0.CO;2.

Orsi, A., T. Whitworth, and W. Nowlin (1995), On the meridional extent and fronts of the Antarctic Circumpolar Current, Deep Sea Res., Part I, 42, 641-673, doi:10.1016/0967-0637(95)00021-W.

Rio, M. H., P. Schaeffer, J. M. Lemoine, and F. Hernandez (2005), Estimation of the ocean mean dynamic topography through the combination of altimetric data, "in-situ measurements and GRACE geoid: From global to regional studies," paper presented at GOCINA International Workshop, Eur. Union, Kirchberg, Luxembourg.

Sprintall, J. (2003), Seasonal to interannual upper-ocean variability in the Drake Passage, J. Mar. Res., 61, 27-57, doi:10.1357/002224003321586408.

Thompson, A. F., S. T. Gille, J. A. MacKinnon, and J. Sprintall (2007), Spatial and temporal patterns of small-scale mixing in Drake Passage, J. Phys. Oceanogr., 37, 572-592, doi:10.1175/JPO3021.1.

Vivier, F., and C. Provost (1999), Direct velocity measurements in the Malvinas Current, J. Geophys. Res., 104(C9), 21,083-21,103, doi:10.1029/1999JC900163.

von Glydenfelt, A. B., E. Fahrbach, M. A. Garcia, and M. Schröder (2002), Flow variability at the tip of the Antarctic Peninsula, Deep Sea Res., Part II, 49, 4743-4766.

von Storch, H., and F. W. Zwiers (1999), Statistical Analysis in Climate Research, 484 pp., Cambridge Univ. Press, Cambridge, UK.

Well, R., W. Roether, and P. Stevens (2003), An additional deep water mass in Drake Passage as revealed by ${ }^{3} \mathrm{He}$ data, Deep Sea Res. Part I, 50, 1079-1098, doi:10.1016/S0967-0637(03)00050-5.

Whitworth, T. I., W. D. J. Nowlin, A. H. Orsi, R. A. Locarini, and S. G. Smith (1994), Weddell Sea Shelf Water in the Bransfield Strait and Weddell-Scotia confluence, Deep Sea Res. Part I, 41, 629-641, doi:10.1016/0967-0637(94)90046-9.

N. Barré, C. Provost, and N. Sennechael, LOCEAN, UMR 7159 CNRS/ UPMC/MNHN/IRD, Université Pierre et Marie Curie, 4 place Jussieu, Tour 45-55, 5E, F-75252 Paris cedex 05, France. (nicolas.barre@loceanipsl.upmc.fr)

J. H. Lee, KORDI, Korean Ocean Research and Development Institute, Ansan P.O. Box 29, Seoul, 425-600 South Korea. 